\title{
Stratospheric variability of wave activity and parameters in equatorial coastal and tropical sites during the West African monsoon
}

\author{
P. Kafando ${ }^{1} \cdot$ F. Chane-Ming ${ }^{2} \cdot$ M. Petitdidier ${ }^{3}$
}

Received: 8 March 2015 / Accepted: 12 July 2015 / Published online: 2 August 2015

(C) The Author(s) 2015. This article is published with open access at Springerlink.com

\begin{abstract}
Recent numerical studies in stratospheric dynamics and its variability as well as climate, have highlighted the need of more observational analyses to improve simulation of the West African monsoon (WAM). In this paper, activity and spectral characteristics of short-scale vertical waves (wavelengths $<4 \mathrm{~km}$ ) are analysed in equatorial coastal and tropical lower stratosphere during the WAM. A first detailed description of such waves over West Africa is derived from high-resolution vertical profiles of temperature and horizontal wind obtained during Intensive Observation Period of the African Monsoon Multidisciplinary Analyses (AMMA) Campaign 2006. Monthly variation of wave energy density is revealed to trace the progression of the inter-tropical convergence zone (ITCZ) over West Africa. Mesoscale inertia gravity-waves structures with vertical and horizontal wavelengths of $1.5-2.5$ and $400-1100 \mathrm{~km}$ respectively and intrinsic frequencies of $1.1-2.2 \mathrm{f}$ or periods $<2$ days
\end{abstract}

This paper is a contribution to the special issue on West African climate decadal variability and its modeling, consisting of papers from the West African Monsoon Modeling and Evaluation (WAMME) and the African Multidisciplinary Monsoon Analyses (AMMA) projects, and coordinated by Yongkang Xue, Serge Janicot, and William Lau.

P. Kafando

kafandopetronille@yahoo.fr

1 Laboratoire de Physique et de Chimie de l'Environnement, Dpt. de Physique, Université de Ouagadougou, UFR-SEA, 03, B.P. 7021, Ouagadougou, Burkina Faso

2 Laboratoire de l'Atmosphère et des Cyclones, Université de la Réunion, UMR 8105, UMR CNRS-Météo FranceUniversité, La Réunion, France

3 Université Versailles Saint-Quentin, CNRS/INSU, LATMOSIPSL, 11 Boulevard d'Alembert, 78280 Guyancourt, France are observed in the tropical LS with intense activity during July and August when the WAM is installed over the tropical West Africa. Over equatorial region, gravity waves with intrinsic frequencies of $1.4-4 \mathrm{f}$ or periods $<5.2$ days, vertical wavelength of $2.1 \mathrm{~km}$ and long horizontal wavelengths of $1300 \mathrm{~km}$ are intense during the WAM coastal phase. From July to October, gravity waves with intrinsic frequencies of $1.2-3.8 \mathrm{f}$ or periods $<6$ days, vertical wavelength of $2.1 \mathrm{~km}$ and horizontal wavelengths of $1650 \mathrm{~km}$ are less intense during the WAM Sahelian phase of the WAM, March-June. Unlike potential energy density, kinetic energy density is observed to be a good proxy for the activity of short-scale vertical waves during the WAM because quasi-inertial waves are dominant. Long-term wave activity variation from January 2001 to December 2009, highlights strong year-toyear variation superimposed on convective activity and quasi-biennial oscillation-like variations especially above tropical stations.

Keywords West African monsoon - Equatorial and tropical waves · Gravity waves - Quasi-biennial oscillation · Stratospheric variability

\section{Introduction}

Atmospheric wavelike structures, with a large variety of scales and properties, affect the dynamics of the atmosphere from local meteorology to global circulation (Chao et al. 2009). They mainly ensure the vertical coupling among atmospheric layers from the troposphere through vertical transport of momentum and chemical constituents.

The role of (1) stratosphere-troposphere coupling and (2) stratospheric dynamics and its variability on climate 
has been highlighted in many recent studies (Gerber et al. 2012; Schirber et al. 2015). The mean state and the variability of the stratosphere affect the tropospheric climate as well as interactions between the tropical troposphere and the mid-latitudes. Maury et al. (2013) recently simulate the tropospheric equatorial variability and stratospheric equatorial waves of the pre-industrial 1000-years using the IPSLCM5 model; the authors point out a misrepresentation of the nature of coupled convectively equatorial waves and the need to have many long-time series data sets. Unlike large-scale equatorial waves, unresolved-scale convective Gravity waves (GWs) suffer from robust parameterization in atmospheric general climate models in order to simulate the quasi-biennial oscillation (QBO) with both realistic periods and amplitudes (Dunkerton 1997; Sato and Dunkerton 1997; Alexander and Holton 1997; Kawatani et al. 2010a, b). Chemistry-climate models also use several GW parameterizations to adjust their stratospheric circulation for accurate simulation of ozone chemistry (Alexander et al. 2010). Nevertheless differences between simulation and observations reveal that improving modeling of multiscale stratospheric waves and their relative contribution is still needed (Xue et al. 2012). Thus Stratospheric Processes and their Role in Climate (SPARC) is a core project of the World Climate Research Programme.

Long time-series observations and their interpretation are also required to improve GW parameterizations for realistic processes. In the tropical belt, many studies using data from ground-based instruments, radiosondes, aircrafts or satellites, investigate characteristics of atmospheric waves and their role in multi-scale convective processes and in atmospheric dynamics. The West African monsoon (WAM) system is a regional meteorological feature which affects the large scale dynamics as well as climate through multiscale interactions and processes (Cook and Vizy 2006). Its establishment is characterized by the seasonal migration of the inter-tropical convergence zone (ITCZ), and a significant annual variation. General circulation models still show deficiencies in simulating the basic features of the WAM at intra-seasonal, seasonal and inter-annual timescales (Bielli et al. 2010). Two keys for climate modeling are the reduction of wind biases with improved estimates of GW forces and the improvement for specifying GWs. To improve the wave-drag parametrizations in climate models, Le Sommer et al. (2006) propose a methodology based on ERA40 reanalysis validated with intensive radiosonde observations to quantify the space-time variability of large-scale inertia GWs in the tropical LS. Geller et al. (2013) suggest comparison of GW fluxes derived from models and observations to improve specifications of $\mathrm{GW}$ sources in climate models. Those authors compared radiosonde momentum flux, provided over North America by Wang et al. (2005), to those derived from satellite observations and models.
One goal of this present study is to provide such data over West Africa in order to be compared to models. More recently, Kim and Chun (2015) estimate the wave forcing using four recent re-analyses. In particular, momentum of unresolved mesoscale GWs, deduced from the residual of the zonal wind tendency equation, suggests GW forcing as the dominant term during the QBO West-East phase.

In general, vertical wavelengths of stratospheric waves derived from satellite, GPS observations and global meteorological models, are greater than $4 \mathrm{~km}$ because of the vertical resolution of instruments and models. In addition the calculation of wave parameters from temperature perturbations only and, longitudinal and latitudinal averages, produce some biases in the variability of regional GW activity of short vertical scales (Sato et al. 2003; Zhang et al. 2012; Das and Pan 2013). So using high-vertical resolution time series of temperature and wind profiles of radiosondes, GW studies could provide information about equatorial and tropical stratospheric waves, with vertical wavelengths shorter than $4 \mathrm{~km}$, and their tropospheric sources (Tsuda et al. 1994a, b; Sato et al. 1994; Wada et al. 1999).

This paper investigates equatorial and tropical (1) wave characteristics and energy densities during the Intensive Observation Period of AMMA Campaign 2006 in the lower stratosphere (LS) and (2) inter-annual variability of stratospheric wave energy densities in connection with the WAM and the quasi-biennial oscillation (QBO). The study is based on radiosonde data launched at six meteorological stations in the belt ranging from $4^{\circ} \mathrm{N}$ to $17^{\circ} \mathrm{N}$ and from $20^{\circ} \mathrm{W}$ to $10^{\circ} \mathrm{E}$. Characteristics of low-frequency GWs, with vertical wavelengths less than $4 \mathrm{~km}$ and periods less than 8 days, are derived from the AMMA radiosonde data. The Wyoming upper-air data base also provides archived radiosonde profiles at these sites from January 2001 to December 2009; those profiles are used to derive long-term variability of stratospheric wave activity at these sites. The paper is organized as follow: Sect. 2 describes the datasets and the methodology for calculation of wave characteristics and energy densities. The meteorological context, the WAM, is described in Sect. 3. Characteristics of waves in tropical and equatorial regions in WAM 2006 are presented and discussed in Sect. 4. Section 5 deals with the inter-annual variability of wave activity. Finally, Sect. 6 gives the summary and the main conclusions.

\section{Datasets and methodology}

\subsection{Datasets}

Two datasets are used in this study. The first dataset, AMMA-2006, includes observations collected in 2006 during the AMMA campaign (Redelsperger et al. 2006; 


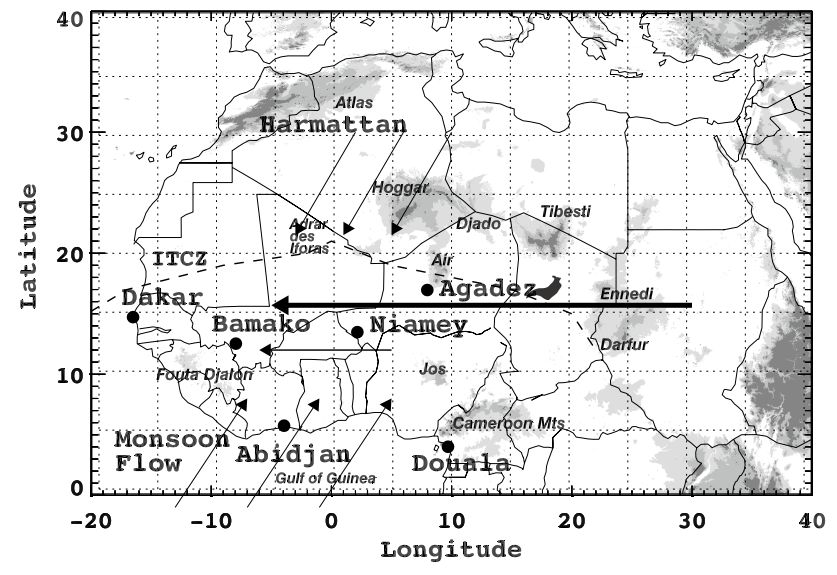

Fig. 1 Location of meteorological stations used for the study and wind fields over the West African region (in July-August): monsoon flow, Harmattan, Tropical Easterly Jet (thick horizontal arrow), African Easterly Jet (thin horizontal arrow); the dashed line indicates the northernmost position of the ITCZ (Inter Tropical Convergence Zone)

Parker et al. 2008; Nuret et al. 2008; Lebel et al. 2010). During the WAM 2006, radiosondes (RS) were launched at six stations in a latitude range between $4^{\circ} \mathrm{N}$ and $17^{\circ} \mathrm{N}$ and a longitude range between $20^{\circ} \mathrm{W}$ and $10^{\circ} \mathrm{E}$ (Fig. 1). Stations at Douala and Abidjan are located in the equatorial areas and, at Bamako, Niamey, Dakar and Agadez in the tropical areas. Periods of observation for each station are mentioned in Table 1. Temperature and horizontal wind profiles with high vertical resolution, i.e. $14 \mathrm{~m}$, are available at least twice daily at 0000 UTC and 1200 UTC (Agustí-Panareda et al. 2010). The total number of RS available for all the stations is around 1246 at 1200 UTC and 1192 at 0000 UTC. After a selection based on the maximum altitude reached, availability of all parameters

Table 1 Coordinates of radiosonde stations and period of observations

\begin{tabular}{lllcl}
\hline Stations & $\begin{array}{l}\text { Latitude } \\
\left({ }^{\circ}\right)\end{array}$ & $\begin{array}{l}\text { Longitude } \\
\left({ }^{\circ}\right)\end{array}$ & $\begin{array}{l}\text { Height } \\
(\mathrm{m})\end{array}$ & $\begin{array}{l}\text { Radiosonde period } \\
(1200 \mathrm{UTC})\end{array}$ \\
\hline Douala & $4.01^{\circ} \mathrm{N}$ & $9.70^{\circ} \mathrm{E}$ & 5 & $\begin{array}{l}\text { March to Septem- } \\
\text { ber } 2006\end{array}$ \\
Abidjan & $5.25^{\circ} \mathrm{N}$ & $3.94^{\circ} \mathrm{W}$ & 7 & $\begin{array}{l}\text { July to September } \\
2006\end{array}$ \\
Bamako & $12.53^{\circ} \mathrm{N}$ & $7.95^{\circ} \mathrm{W}$ & 377 & $\begin{array}{l}\text { July } 2006 \text { to July } \\
2007\end{array}$ \\
Niamey & $13.48^{\circ} \mathrm{N}$ & $2.16^{\circ} \mathrm{E}$ & 222 & $\begin{array}{c}\text { January } 2006 \text { to } \\
\text { December } 2007\end{array}$ \\
Dakar & $14.72^{\circ} \mathrm{N}$ & $17.50^{\circ} \mathrm{W}$ & 28 & $\begin{array}{c}\text { January } 2006 \text { to } \\
\text { November } 2007\end{array}$ \\
Agadez & $16.96^{\circ} \mathrm{N}$ & $7.98^{\circ} \mathrm{E}$ & 501 & $\begin{array}{c}\text { January to October } \\
2006\end{array}$ \\
& & & & $\begin{array}{c}\text { July to September } \\
2007\end{array}$ \\
\hline
\end{tabular}

and data quality, the number of RS becomes 747 at 1200 UTC and 520 at 0000 UTC. Then only the time series at 1200 UTC is studied.

The second dataset comes from the Wyoming upper-air database, already used in Kafando et al. (2008). Radiosonde profiles with a $300-\mathrm{m}$ vertical resolution permit to produce a 9-year climatology of GW energy densities from January 2001 to December 2009 at the equatorial and tropical sites, Douala and Niamey, respectively.

\subsection{Methodology and example}

Data processing applied on vertical profiles of horizontal wind and temperature perturbations has been commonly used in the framework of the Stratospheric Processes And their Role in Climate (SPARC) initiative for climatological studies of low-frequency GWs (Allen and Vincent 1995; Vincent and Alexander 2000; Wang and Geller 2003; Chane-Ming et al. 2007). GW characteristics and energy densities for waves with short vertical wavelengths of $1-4 \mathrm{~km}$ are computed at altitudes between 19 and $23 \mathrm{~km}$ in the LS above the tropopause height because more than $70 \%$ of soundings at 1200 UTC reach the altitude of $23 \mathrm{~km}$.

However a test on a set of profiles in the height range of $19-25 \mathrm{~km}$ leads to similar results than those obtained in the height range of $19-23 \mathrm{~km}$.

Sounding profiles at 1200 UTC are first re-sampled with a $100-\mathrm{m}$ interval height using a cubic spline interpolation at heights between 19 and $23 \mathrm{~km}$. Then temperature are selected within $\pm 3 \sigma$ of the mean yearly temperature and horizontal wind profiles within $\pm 3 \sigma$ of the mean monthly horizontal winds because of the seasonal variation of wind (Kafando et al. 2008). A total of 747 vertical profiles among 1246 are selected in 2006 for the present study (Table 2). Background profiles of temperature and horizontal winds are first derived from applying a second-order polynomial in the $19-23 \mathrm{~km}$ height interval. Then, the resulting background profiles are subtracted from original re-sampled profiles to produce perturbation profiles. Wave activity with shortvertical wavelengths is estimated using the total energy density $\left(\mathrm{E}_{\mathrm{T}}\right)$ (Eq. 1) resulting from the sum of kinetic and potential energy densities, hereafter noted KE and PE respectively (Eq. 2).

$E_{T}=K E+P E$

$K E=\frac{1}{2}\left(\overline{u^{\prime 2}}+\overline{v^{\prime 2}}\right) \quad$ and $\quad P E=\frac{1}{2} \frac{g^{2}}{N^{2}} \overline{\hat{T}^{\prime 2}}$

$U^{\prime}, v^{\prime}, T^{\prime}$ are respectively the perturbations of zonal and meridional winds, and temperature respectively. $g$ is the gravitational constant, $N$ is the buoyancy 
Table 2 Number of selected profiles per month in the lower stratosphere $(19-23 \mathrm{~km})$ at 1200 UTC from AMMA 2006 database

\begin{tabular}{lrrrrrrrrrrrrr}
\hline Stations & J & F & M & A & M & J & J & A & S & O & N & D & Total \\
\hline Douala & 0 & 0 & 4 & 17 & 25 & 25 & 20 & 4 & 10 & 0 & 0 & 0 & 105 \\
Abidjan & 0 & 0 & 0 & 0 & 0 & 0 & 8 & 24 & 19 & 12 & 2 & 0 & 65 \\
Bamako & 0 & 0 & 0 & 0 & 0 & 0 & 12 & 7 & 14 & 18 & 12 & 10 & 73 \\
Niamey & 4 & 15 & 24 & 17 & 9 & 18 & 19 & 18 & 20 & 1 & 21 & 11 & 177 \\
Dakar & 19 & 21 & 18 & 14 & 15 & 4 & 9 & 15 & 14 & 9 & 9 & 9 & 156 \\
Agadez & 8 & 23 & 21 & 24 & 24 & 21 & 18 & 17 & 12 & 3 & 0 & 0 & 171 \\
Total & 31 & 59 & 67 & 72 & 73 & 68 & 86 & 85 & 89 & 43 & 44 & 30 & 747 \\
\hline
\end{tabular}

frequency, $\hat{T}^{\prime}$ is the temperature perturbation normalised by the temperature background $\left(\hat{T}^{\prime}=\frac{T^{\prime}}{\bar{T}}\right)$, called normalized temperature perturbation. The bar over the perturbation terms means an averaging over the altitude range.

Spectral characteristics of GWs are computed using conventional methods, described in Chane Ming et al. (2010). They are based on the GW spectra theory, the rotary spectra and Stokes' parameter analyses (Vincent et al. 1997; Eckermann 1996). Normalized temperature power spectral density is firstly computed by applying a Fast Fourier Transform (FFT) to temperature perturbation normalized by the temperature background. Then the spectrum is fitted to the modified-Desaubies model to extract dominant vertical wavenumber, $m$ (VanZandt 1982; VanZandt and Fritts 1989; Desaubies 1976). Fourier-based method of Stokes parameters provides intrinsic angular frequency $\left(\omega^{*}\right)$ and period of dominant GWs. Horizontal wavenumber $\left(\mathrm{k}_{\mathrm{h}}\right)$ is then derived from linear relation of GW dispersion (Gill1982):

$k_{h}^{2}=m^{2} \frac{\omega^{* 2}-f^{2}}{N^{2}-\omega^{* 2}}$

where $f$ is the inertial frequency and $N$ the buoyancy frequency.

Horizontal wavelength and phase speed are defined as: $\lambda_{\mathrm{h}}=2 \pi / k_{\mathrm{h}}$ and $v_{\mathrm{h}}=\omega^{*} / k_{\mathrm{h}}$. The mean direction of horizontal propagation (Eq. 4) (clockwise from North) is computed from velocity and normalized temperature perturbations, using the Hilbert-transform of temperature perturbations (Vincent et al. 1997).

$\Phi=a \tan \left(\frac{\overline{u^{\prime} \widehat{T}_{+90}^{\prime}}}{\overline{v^{\prime} \widehat{T}_{+90}^{\prime}}}\right)$

$\mathrm{U}^{\prime}$ and $\mathrm{v}^{\prime}$ are zonal and meridional wind perturbation respectively and $\mathrm{T}^{\prime}{ }_{+90^{\circ}}$ is the value of temperature perturbation after shifting phase by $+90^{\circ}$ via the Hilbert transform.
In this study, unlike previous studies, GW parameters are first derived for each profile and monthly values are derived from median values.

For example, Fig. 2 displays typical vertical profiles of perturbations in the tropical LS above Niamey on July during WAM 2006. On 2 July 2006, dominant modes with vertical wavelengths of $2.3 \mathrm{~km}$ are embedded on profiles below and above altitudes of $22 \mathrm{~km}$ respectively. The total energy densities, $\mathrm{E}_{\mathrm{T}}$, are $21.2 \mathrm{~J} \mathrm{~kg}^{-1}$ with a strong contribution of $\mathrm{KE}\left(19 \mathrm{~J} \mathrm{~kg}^{-1}\right)$ in comparison with $\operatorname{PE}\left(2.3 \mathrm{~J} \mathrm{~kg}^{-1}\right)$. Phase relations between zonal, meridional wind and temperature perturbations agree with linear GW polarization relations. Indeed the hodograph of the horizontal wind perturbation shows evidence of an elliptical structure with vertical wavelength of $\sim 2.6 \mathrm{~km}$ at heights of $21 \mathrm{~km}$. The axis ratio of horizontal wind perturbations is about 1.3 which corresponds to a quasi-inertial period of 1.7 days. Spectral characteristics indicate the presence of an inertia GW (IGW) with vertical and horizontal wavelengths of 2.1 and $1800 \mathrm{~km}$ respectively (Table 3 ). The fraction of upward energy propagation (Fup) is derived from the rotary spectra analysis which decomposes a motion in a plane into its clockwise and counter-clockwise rotating components (Vincent 1984). A fraction of upward energy propagation (Fup) of $89 \%$ suggests a tropospheric source of stratospheric GW.

Wave horizontal propagation is west-southwards with a horizontal phase speed of $11.9 \mathrm{~m} \mathrm{~s}^{-1}$. Zonal (meridional) mean winds are westwards (northwards) in the height range of 2-17 km and vary between -11 and $-8 \mathrm{~m} \mathrm{~s}^{-1}$ (1 and $3 \mathrm{~m} \mathrm{~s}^{-1}$ ) at altitudes of 6-17 km. The steady meridional background wind behaviour above Niamey on 2 July 2006 allows IGWs generated in the troposphere with such a phase speed to propagate into the LS. Above altitudes of 22-23 km, wave amplitudes are smaller where the westward mean zonal wind decreases with height. A decrease in wave amplitude and vertical wavelength above the altitude of $21 \mathrm{~km}$ suggests the presence of a critical layer for such wave induced by the background wind. 


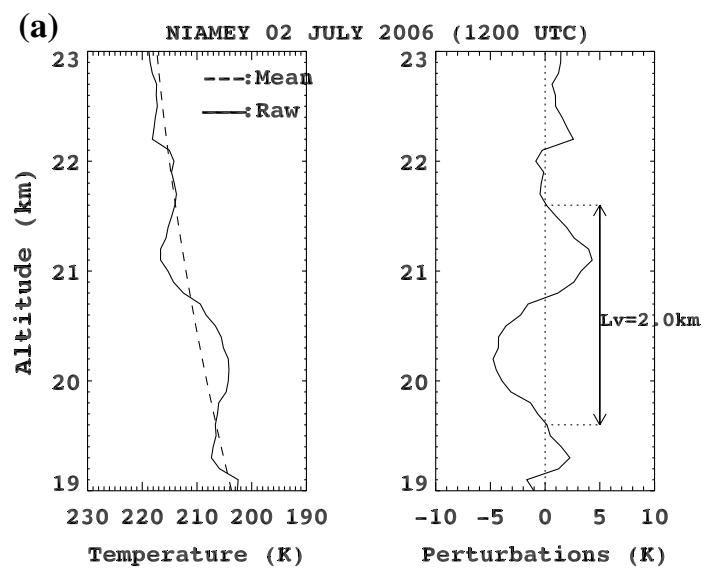

(b)
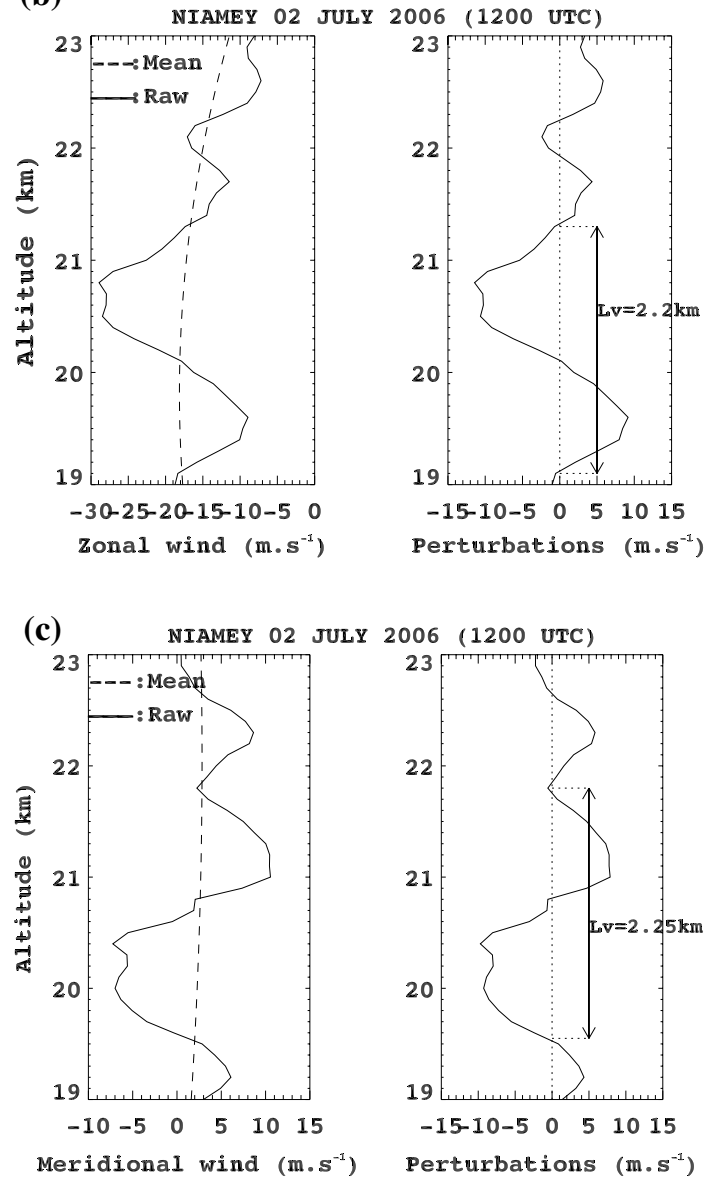

Fig. 2 Radiosonde vertical profiles of a temperature, $\mathbf{b}$ zonal and c meridional wind and perturbations in the lower stratosphere (19$23 \mathrm{~km}$ ) above Niamey $\left(13.47^{\circ} \mathrm{N} ; 2.16^{\circ} \mathrm{E}\right)$ on 2 July 2006 at 1200 UTC during AMMA Campaign. On the left panel, dashed line represents the mean and solid line the raw profile

\section{Characteristics of WAM}

\subsection{Annual cycle of the WAM}

West Africa area (Fig. 1) is delimited in the South by the Gulf of Guinea, in the North by the Sahara desert and the Atlas mountain range $(4000 \mathrm{~m})$, in the West by the Atlantic Ocean. In the East direction there is a succession of mountains, South-East North-West oriented: Mount Cameroon $\left(4.22^{\circ} \mathrm{N}, 9.17^{\circ} \mathrm{E}, 4070 \mathrm{~m}\right)$, Darfur $\left(13.66^{\circ} \mathrm{N}, 24^{\circ} \mathrm{E}\right.$, $3000 \mathrm{~m})$, Tibesti $(3415 \mathrm{~m})$, Airr $\left(19^{\circ} \mathrm{N}, 8.5^{\circ} \mathrm{E}, 2000 \mathrm{~m}\right)$, and Hoggar (2918 m). The Fouta Djalon $\left(10^{\circ} \mathrm{N}, 10^{\circ} \mathrm{W}, 1000 \mathrm{~m}\right)$ is in the South West. The succession of mountain ranges and basins affects the migration of the ITCZ as a function of the apparent sun motion and the low-level atmospheric circulation.

Thorncroft et al. (2011) describes the annual cycle of the WAM through five key phases in relation with the rainfall belt progression, associated to the ITCZ:

1. An oceanic phase between November and mid-April when the rain belt peaks at North of the Equator $\left(\sim 1^{\circ} \mathrm{N}\right)$.

2. A coastal phase between mid-April and the end of June when rainfall distribution peaks over the African coast around $4^{\circ} \mathrm{N}$. This phase is associated with an intensification of southerlies in the low troposphere which increases the coastal convergence and strengthens advection of moisture toward the coast and then inland.

3. There is a transitional phase from June to the first half of July, with weak convection and rainfall intensity decrease. Dry-air intrusions are proposed to explain the characteristics of this transitional phase and the onset date of monsoon (Flaounas et al. 2012).

4. A Sahelian phase takes place between mid-July and September when the rainfall peak is more intense and located in the Sahelian region around $10^{\circ} \mathrm{N}$. During this period, a large anomaly of the West African Heat Low (WAHL) is detected over the Hoggar, inducing a strong convergent wind field anomaly, an increase of the monsoon flow and a northward anomaly in the position of the Inter Tropical Discontinuity (Lavaysse et al. 2009).

5. Then from mid-September, earlier or later according to the year, until November the rain belt of the ITCZ moves slowly back to the Guinea Gulf. 
Table 3 Gravity wave parameters derived from AMMA 2006 database above Niamey in the LS (19-23 km) at 1200 UTC on 02 July 2006

\begin{tabular}{lllllllllll}
\hline Parameters & $\mathrm{E}_{\mathrm{T}}^{\mathrm{a}}$ & $\mathrm{KE}^{\mathrm{b}}$ & $\mathrm{PE}^{\mathrm{c}}$ & $\mathrm{Fup}^{\mathrm{d}}$ & $\mathrm{Phi}^{\mathrm{e}}$ & $\omega^{*} / \mathrm{f}^{\mathrm{f}}$ & $\mathrm{T}^{\mathrm{g}}$ & $\lambda v^{\mathrm{h}}$ & $\lambda_{\mathrm{h}}^{\mathrm{i}}$ & $\mathrm{Vph}^{\mathrm{j}}$ \\
\hline Values & 21.2 & 19.0 & 2.3 & 0.89 & 199.4 & 1.3 & 41.52 & 2.1 & 1800 & 11.9 \\
\hline
\end{tabular}

${ }^{\text {a }} \mathrm{E}_{\mathrm{T}}$ is the total energy density $\left(\mathrm{J} \mathrm{kg}^{-1}\right)$

${ }^{b} \mathrm{KE}$ is the kinetic energy density $\left(\mathrm{J} \mathrm{kg}^{-1}\right)$

${ }^{c} \mathrm{PE}$ is the potential energy density $\left(\mathrm{J} \mathrm{kg}^{-1}\right)$

${ }^{d}$ Fup is the fraction of wave upward propagating energy

${ }^{\mathrm{e}}$ Phi is the horizontal direction of propagation clockwise from North $\left(^{\circ}\right)$

f $\omega * / f$ is the ratio of the intrinsic frequency to the inertial frequency

$\mathrm{g} \mathrm{T}$ is the period (h)

$\mathrm{h} \lambda_{\mathrm{v}}$ is the vertical wavelength $(\mathrm{km})$

i $\lambda_{\mathrm{h}}$ is the horizontal wavelength $(\mathrm{km})$

$\mathrm{j} \mathrm{Vph}$ is the horizontal phase speed $\left(\mathrm{m} \mathrm{s}^{-1}\right)$

During the Sahelian phase of the WAM in 2006, the monsoon winds are weaker than the long-term mean in June and increase later to produce stronger westerly inflow of moisture in August and September (Janicot et al. 2008). Regarding climatology mean values, in 2006 the WAM onset occurs later with a 10-day delay because of an anomalous pattern of the atmospheric circulation during 10 days between 25 June and 3 July 2006 (Drobinski et al. 2009) and the monsoon still persists in September. Convective activity is near-normal but a large-scale rainfall excess occurs at a latitude of $15^{\circ} \mathrm{N}$.

While the ITCZ progression follows the apparent sun motion, interactions with land, atmosphere and ocean perturb ITCZ evolution in addition to the topography. The WAHL and the Atlantic cold tongue play a major role in controlling the inland penetration of humidity and convection (Caniaux et al. 2011; Lavaysse et al. 2009; Okumura and Xie 2004). Both the WAHL and the Atlantic cold tongue develop in spring and become hottest or coldest in summer, respectively. Climatological observations of WAHL from 1979 to 2001 indicate that from November to March, the WAHL is located in the eastern part of Africa, south of the Darfur Mountains centred around $8^{\circ} \mathrm{N}$, $20^{\circ} \mathrm{E}$. In April the WAHL begins to move north-westward to latitudes of $22^{\circ}-27^{\circ} \mathrm{N}$ over the Sahara. It is found that the jump of the WAHL from its intermediate position $\left(19^{\circ}-22^{\circ} \mathrm{N}\right)$-in the vicinity of Dakar-to its Saharan position $\left(22^{\circ}-27^{\circ} \mathrm{N}\right)$ coincides with the onset of the WAM. The jump occurs around 5 days before the climatological monsoon onset (Lavaysse et al. 2009).

The African Easterly Jet (AEJ) in the lower troposphere and the Tropical Easterly Jet (TEJ) in the upper troposphere(UT), near the tropopause, follow the same annual cycle with a displacement from the Gulf of Guinea region to North latitudes around $10^{\circ}-15^{\circ}$ during monsoon period in the West Africa region. The TEJ, located around 100-200 hPa (i.e. near the tropopause) and well extended
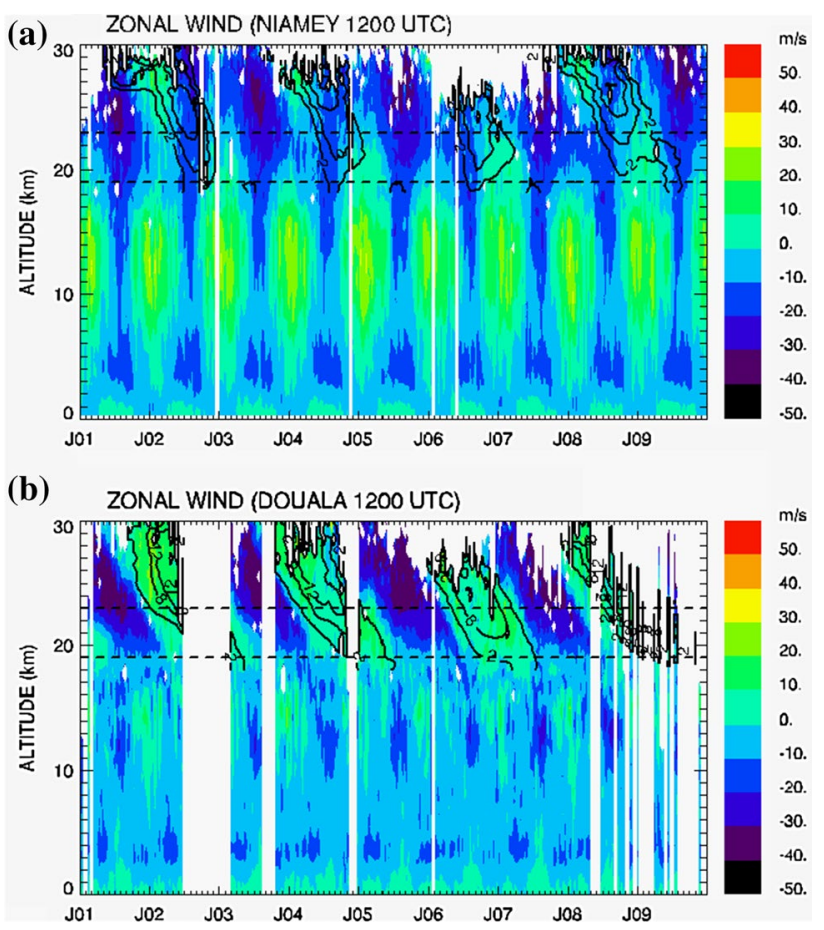

Fig. 3 Time-Altitude zonal wind for 2001-2009 at 1200 UTC above a Niamey and b Douala. Contours visualize 1.5-3.5 year bandpass filtered zonal wind for eastward speed $\geq 2 \mathrm{~m} \mathrm{~s}^{-1}$ above $19 \mathrm{~km}$ heights. Dashed lines indicate the altitude range of $19-23 \mathrm{~km}$

Eastwards, starts to be observed during the transitional phase over West Africa (phase 3) and enhances in July and August (phase 4) as well as the convective activity above tropical area. In 2006, from July to August, the TEJ varies between -10 and $-12 \mathrm{~m} \mathrm{~s}^{-1}$ and extends over West Africa and Westwards as far as $40^{\circ} \mathrm{W}$. The TEJ becomes also larger in latitude and its intensity strengthens with values around $-12 \mathrm{~m} \mathrm{~s}^{-1}$ in the tropical area and around $-14 \mathrm{~m} \mathrm{~s}^{-1}$ above Douala. The retreat stage, phase 5, in September, above West Africa was characterized by the 
TEJ moving southwards, its latitudinal extension reduced as well as its intensity with speeds of $-6 \mathrm{~m} \mathrm{~s}^{-1}$ above the tropical zone and around $-12 \mathrm{~m} \mathrm{~s}^{-1}$ above the equatorial area respectively. On Fig. 3, jets are observed at around $5 \mathrm{~km}$ the westward-wind AEJ, at $12 \mathrm{~km}$ the Sub-TropicalWesterly Jet and the westward-wind TEJ around $15 \mathrm{~km}$.

In the equatorial and tropical stratosphere the dominant dynamical feature is the QBO, alternate bands of westward and eastward zonal winds with a quasi-biennial periodicity (Baldwin et al. 2001). The impact of QBO on the WAM remains unclear because WAM parameters, like precipitation, onset date... vary from year-to-year but not following the QBO periodicity. However convection in the troposphere during the WAM are likely to generate a broad spectrum of waves that propagate vertically to interact with the QBO by transporting and mostly depositing zonal momentum at stratospheric levels.

Figure 3 shows over 9 years the zonal wind at Niamey, tropical site, and Douala, equatorial site. The QBO is evident on the equatorial site Douala. The annual variation

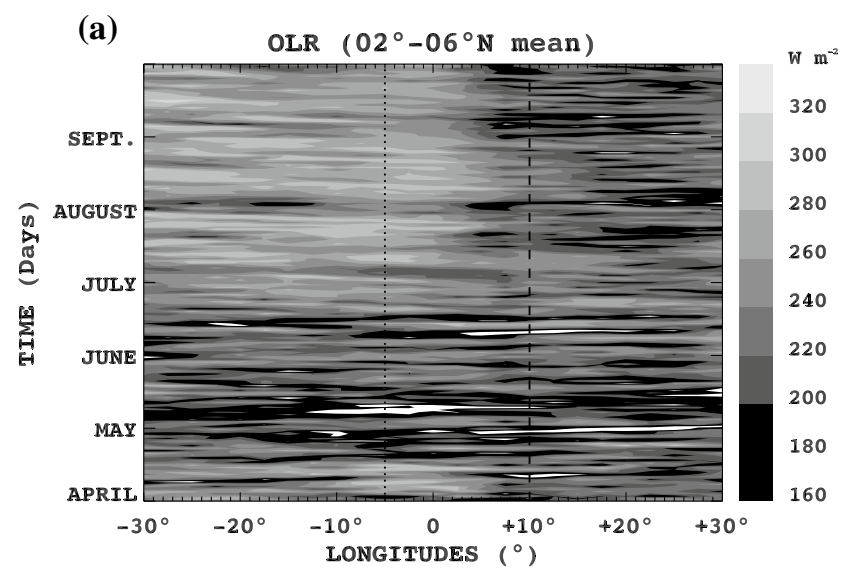

(b)

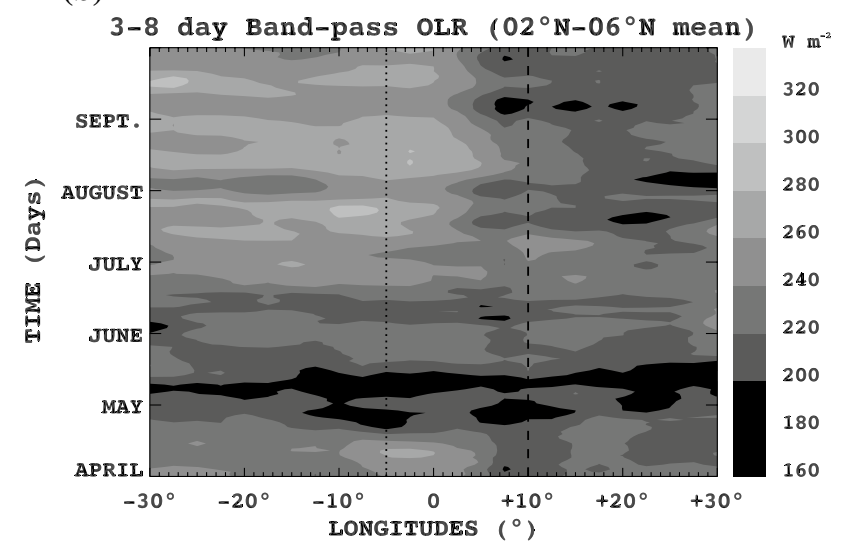

Fig. 4 Time-longitude Hovmöller diagram of OLR at longitudes between $30^{\circ} \mathrm{W}$ and $30^{\circ} \mathrm{E}$ from 1 April to 30 September 2006. Daily OLR averaged over the latitudes of $2^{\circ}-6^{\circ} \mathrm{N}$ : a OLR, b $3-8$ day bandpass filtered OLR, and averaged over the latitudes of $10^{\circ}-15^{\circ} \mathrm{N}$ : c of tropical stratospheric wind is filtered to derive the biannual variation. Contours on Fig. 3a also visualize the QBO E-Phases which are superimposed on the zonal wind variation above $19 \mathrm{~km}$ altitude above tropical site Niamey.

\subsection{Description of convective structures above West Africa}

Convection is the major source of short vertical scale waves during the WAM period as well as in other tropical and equatorial areas (Salby and Garcia 1987; Pandya and Alexander 1999; Mc-Landress et al. 2000; Berès et al. 2002). Daily OLR data provided by NOAA satellites (Liebmann and Smith 1996) are used as a proxy to visualize spatiotemporal distribution of convective structures over West Africa tropical and equatorial areas from May to September 2006. OLR daily data are averaged over the two latitudinal belts, $2^{\circ}-6^{\circ} \mathrm{N}$ and $10^{\circ}-15^{\circ} \mathrm{N}$, corresponding to equatorial and tropical area respectively (Fig. $4 \mathrm{a}, \mathrm{c}$ ).
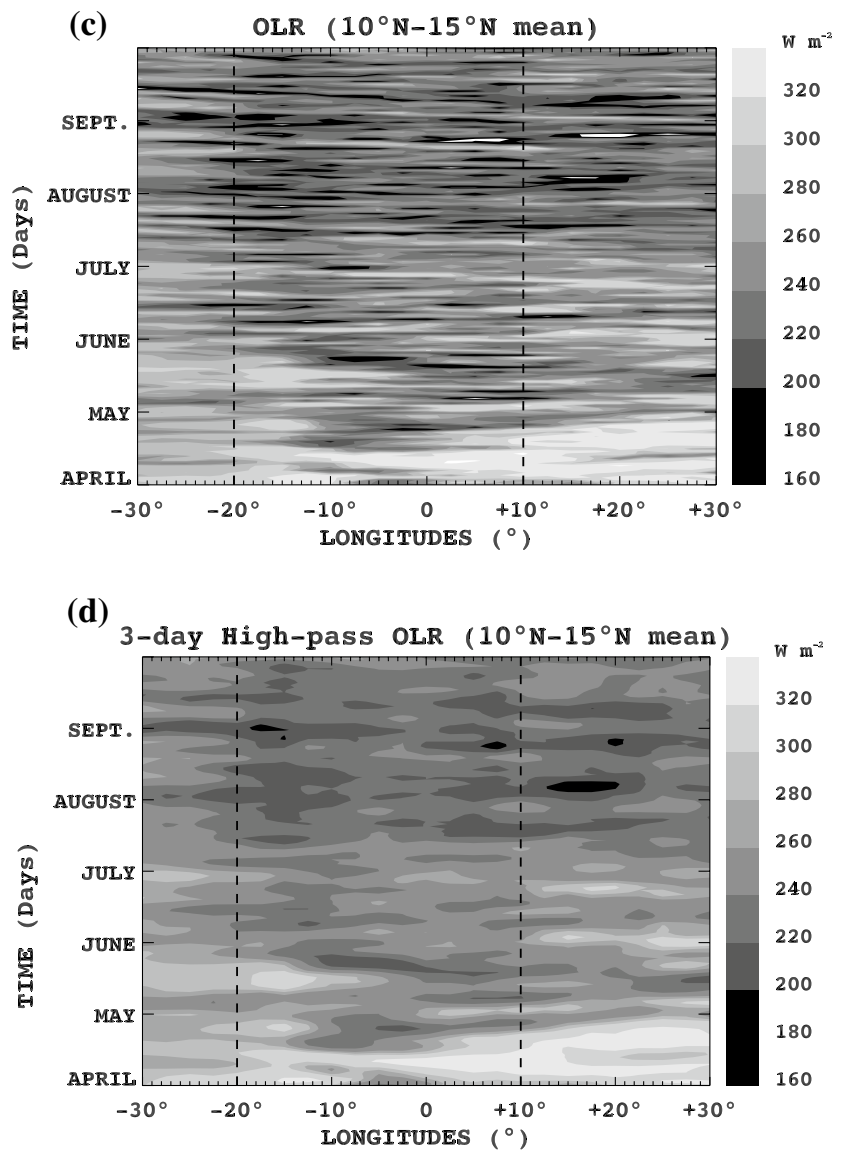

OLR, d 3-day high-pass filtered OLR. On a and b, the dashed line indicates the longitude of Douala and the dotted line the longitude of Abidjan; on $\mathbf{c}$ and $\mathbf{d}$ dashed lines delineate the longitudinal borders of the studied tropical belt 
On the Hovmöller time-longitude diagram (Fig. 4a), minimum OLR values indicate dominant convective structures over equatorial region. The OLR data are band-pass filtered to preserve equatorial convective structures with inertial periods of 3-8 days. Indeed, several studies identified IGWs with periods between 3 and 8 days in the equatorial LS using radiosonde observations (Baldwin et al. 2001; Le Sommer et al. 2006). Filtered OLR shows evidence of convective structures with periods of 3-8 days over the ocean from April to the end of June during the oceanic, coastal and transitional phases described in 43.1. After June the convection is more important on land above the surrounding area of Douala at longitude of $9.70^{\circ} \mathrm{E}$ (Fig. 4b). A different behaviour is observed above Abidjan $\left(3.94^{\circ} \mathrm{W}\right)$ for which deepest convective structures with 3-8 day periods are only localized in mid-April-June and weak convection from July to September.

In the tropical area, convective structures are observed in May in the interval $10^{\circ} \mathrm{W}-10^{\circ} \mathrm{E}$ and during the July-September period they are observed in the entire longitudinal belt $\left(30^{\circ} \mathrm{W}-30^{\circ} \mathrm{E}\right)$ (Fig. $\left.4 \mathrm{c}\right)$. In the tropical area the highest inertial period being 2.27 days (at Bamako) so wave intrinsic periods are expected to be shorter or near 2.27 days. Thus the OLR is high-pass filtered to extract structures with intrinsic periods $\leq 3$ days (Fig. 4d). In July to September during the Sahelian phase, deep convection covers the land area, $20^{\circ} \mathrm{W}-30^{\circ} \mathrm{E}$ that includes the three tropical stations Dakar, Bamako and Niamey; Agadez in the Sahel being at the higher latitude, $17^{\circ} \mathrm{N}$, not included in this figure. In the surrounding of Dakar $\left(17.50^{\circ} \mathrm{W}\right)$ there is weak or no convection until the end of June over the ocean and on the coast; after June, Dakar is in the convective area towards the East of Dakar. Bamako $\left(7.95^{\circ} \mathrm{W}\right)$ is in convective from mid-April to September whose intensity is higher from July to September. Niamey $\left(2.16^{\circ} \mathrm{E}\right)$ is in a convection area only at the end of April and in June the convection is weak.

\section{Characteristics of waves in 2006}

\subsection{West Africa tropical region}

In the tropical LS during WAM, the QBO is superimposed on westward flow. At heights of $19-23 \mathrm{~km}$, the zonal wind is westwards until August 2006 with an eastward shear while the QBO is in the W-phase (westerly) from March 2006 at $23 \mathrm{~km}$ height in the equatorial LS with eastward zonal winds (Fig. 3). Above Niamey the zonal wind varies between -13 and $-2.5 \mathrm{~m} \mathrm{~s}^{-1}$ at $21 \mathrm{~km}$ from May to September 2006.

Tropical stations, located at latitudes between $12.53^{\circ} \mathrm{N}$ and $16.96^{\circ} \mathrm{N}$ and longitudes between $2.16^{\circ} \mathrm{E}$ and $17.50^{\circ} \mathrm{W}$ in West Africa, have specific meteorological characteristics.
Bamako $\left(12.53^{\circ} \mathrm{N}, 7.95^{\circ} \mathrm{W}\right)$ is located in the southwest of Mali on the banks of the Niger River in a basin surrounded by hills. The site is localized in the most southern part of the African Sahel and profits from a rather wet tropical climate with one dry season (from October/November to May/June) and a rainy season (from June to September/ October), the monsoon period.

Niamey $\left(13.48^{\circ} \mathrm{N}, 2.16^{\circ} \mathrm{E}\right)$ is located in the south western region of Niger in a semi-arid tropical climate, the Sahel, with the town crossed by the Niger River. Its climate is characterized by two well-marked seasons. The dry season extends from October to April/May and is characterized by dust and sandstorms, and the absence of precipitations. The rainy season extends from June to September that is the monsoon period with strongest daily precipitations in July and in August.

Dakar $\left(14.72^{\circ} \mathrm{N}, 17.5^{\circ} \mathrm{W}\right)$ is on the Atlantic coastline. Whereas this site is located in the Sahel, its advanced position in the Atlantic Ocean induces a microclimate of coastal type influenced by the ocean cooling and the monsoon winds. Two seasons are observed: a dry season, from November to May and a rainy season, from June/July to October, the monsoon period. The rainy season occurs with a delay of one month in comparison with the others sites located in the Sahel.

Agadez $\left(16.96^{\circ} \mathrm{N}, 7.98^{\circ} \mathrm{E}\right)$ is in a dry region, the Sahel, close to the Air Mountains with few precipitations in July and August. This situation is the results of the WAHL, located North of Agadez at around $22^{\circ} \mathrm{N}$, that has a significant impact on the West African monsoon and is also likely to impact convection and rainfall over the Sahel (Lavaysse et al. 2010).

\subsubsection{Wave energy densities}

Figure 5 shows seasonal variation of the OLR, $\mathrm{E}_{\mathrm{T}}, \mathrm{PE}$ and KE above 4 tropical stations. For each station, the monthly median values and their first quartiles (error bar) are plotted for the OLR; while for the other parameters, $\mathrm{E}_{\mathrm{T}}, \mathrm{KE}$ and $\mathrm{PE}$, their monthly median and quartiles are computed over available profiles, indicated below the abscissa line. The superimposition of the $\mathrm{E}_{\mathrm{T}}, \mathrm{KE}$ and $\mathrm{PE}$ seasonal variations of the 4 tropical sites (not shown) reveals a similar behaviour with maximum $\mathrm{E}_{\mathrm{T}}>20 \mathrm{~J} \mathrm{~kg}^{-1}$ in August, an increase during the pre-onset of the monsoon, and lower values ( $<$ half of maximum values) during the dry season from October to April 2006. The low value in June, observed in Dakar, might be not significant considering the number of samples in June 4. However its climatology points out a similar delay for the rainy season beginning. The WAHL location, North of Dakar before moving to north east over the Hoggar, and the cold oceanic tongue, might explain the onset delay in Dakar by inhibiting the convection. 
(a) GW ENERGY DENSITIES IN THE LS (2006)

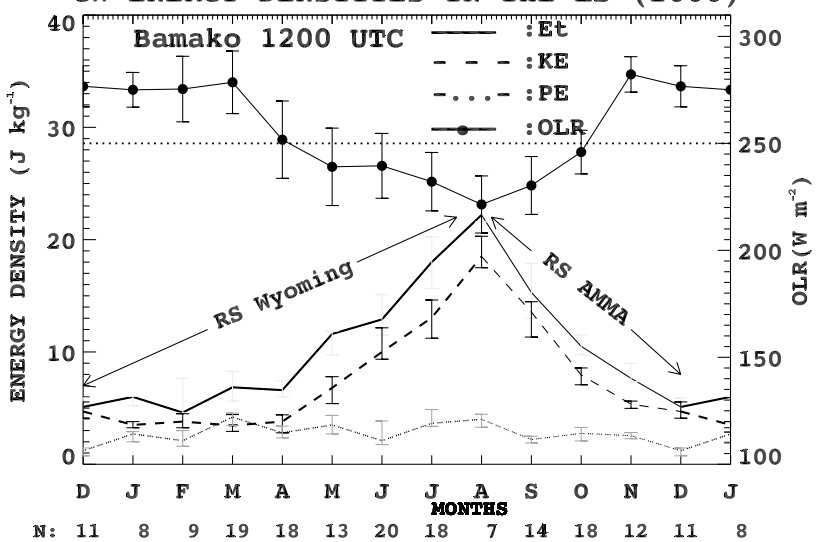

(b) GW ENERGY DENSITIES IN THE LS (2006)

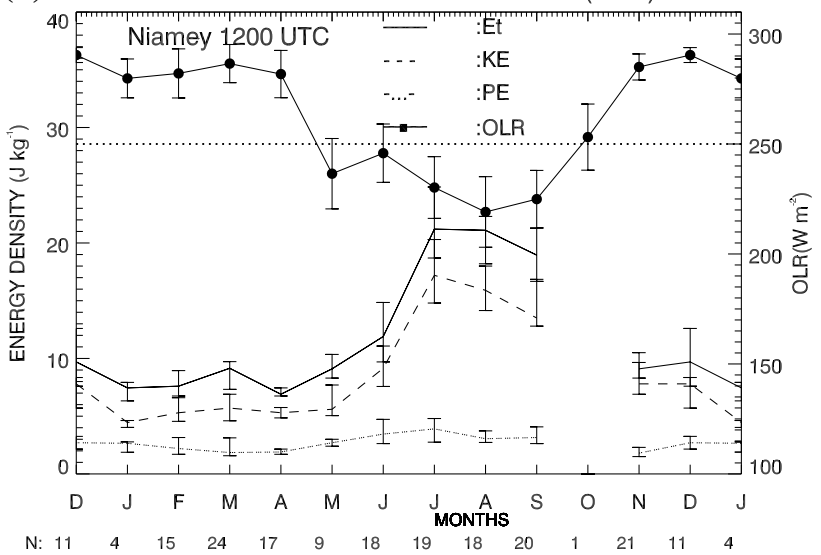

Fig. 52006 annual cycle of wave total energy (solid line), kinetics energy (dashed line), and potential energy (dash dot dot) densities monthly median values (left hand ordinate) and outgoing longwave radiation (black circles) (right hand ordinate) in the LS above the West African tropical area: a Bamako (for January to August energy densities based on radiosonde data from the Wyoming University

During the dry season, $\mathrm{E}_{\mathrm{T}}$ is varying between $4.6 \pm 3.1$ and $9.7 \pm 5.0 \mathrm{~J} \mathrm{~kg}^{-1}$. During the WAM, $\mathrm{E}_{\mathrm{T}}$ is maximum in July and August with amplitude ranging between $14.2 \pm 3.9$ and $23.1 \pm 5.2 \mathrm{~J} \mathrm{~kg}^{-1}$. Previous studies provide same order values during dry (winter) and wet (summer) season in the tropics ranging between $9-12 \mathrm{~J} \mathrm{~kg}^{-1}$ and, 12-26 $\mathrm{J} \mathrm{kg}^{-1}$ respectively (Allen and Vincent 1995; Vincent and Alexander 2000; Chane-Ming et al. 2007; Kafando et al. 2008).

During the WAM period, KE is the major contributor of the $\mathrm{E}_{\mathrm{T}},(85-90 \%)$ and low values of PE are observed throughout the year $\left(\sim 2-4 \mathrm{~J} \mathrm{~kg}^{-1}\right)$. The ratio $p=K E / P E$ is higher than 2.5 and reaches around 4 in July and August; the expected value being in-between 1 and 2 assuming GW total energy spectrum scaling at $\omega^{-5 / 3}$. Hertzog et al. (2002) suggest that such high values of $p$ are due to an enhancement of wave activity at near inertial frequencies.
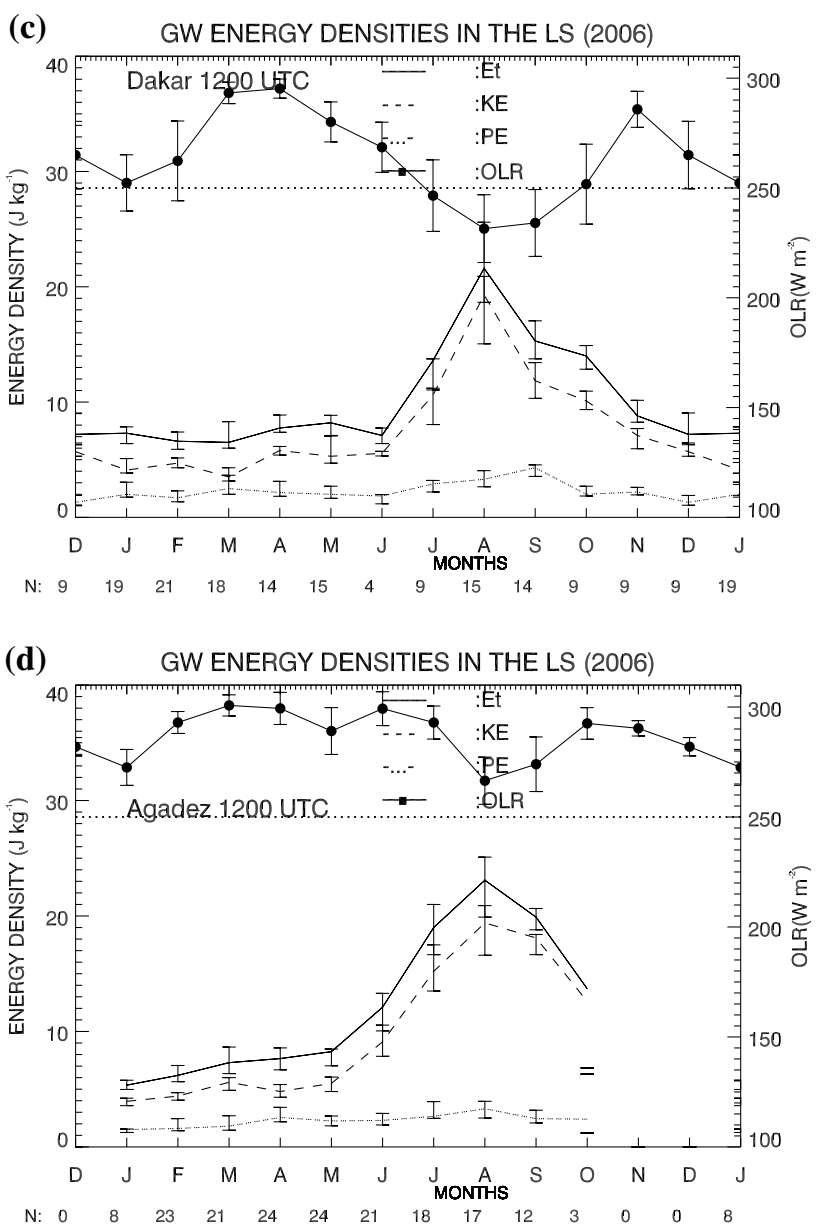

database are used to supply the lack of data from AMMA Campaign Radiosonde observations), b Niamey, c Dakar, and d Agadez (for b, c and $\mathbf{d}$, energy densities are based on AMMA Campaign Radiosonde observations). $\mathrm{N}$ indicates the number of profiles per month used to compute wave energy densities and the dotted horizontal line indicates the threshold of convection

The monthly OLR values are plotted on Fig. 5 over the four sites at a resolution of $2.5^{\circ} \times 2.5^{\circ}$ latitude-longitude to complement the convection map over the this tropical area (Fig. 4c, d). Strongest convection occurs from May to October in Bamako and Niamey, from July to October in Dakar. The clear anti-correlation between OLR and $\mathrm{E}_{\mathrm{T}}$ supports that the wave activity during the WAM is indeed related to the convection. The OLR seasonal variation in Agadez presents no evidence of local convection; its strong difference from the three other sites can be only explained by its location in the Sahel. However similar global behaviour of the seasonal variations of $\mathrm{E}_{\mathrm{T}}, \mathrm{KE}$ and $\mathrm{PE}$ is observed and is explained by distant convective sources all over the tropical West Africa (Janicot et al. 2008).

Contributions of wave energy density from other sources are considered minor in regards to convection during the WAM. Indeed the TEJ could produce some GWs during the 
Table 4 Median values (from May to September 2006) of lower stratosphere GW parameters for tropical sites

\begin{tabular}{|c|c|c|c|c|c|c|c|c|c|c|}
\hline Parameters & $\mathrm{f}^{\mathrm{a}}$ & $\mathrm{T}_{\text {inertial }}^{\mathrm{b}}$ & $\mathrm{N}^{\mathrm{c}}$ & $\omega^{*} / f^{d}$ & $\mathrm{E}_{\mathrm{T}}^{\mathrm{e}}$ & Fup $^{f}$ & $\mathrm{~T}^{\mathrm{g}}$ & $\lambda_{\mathrm{v}}^{\mathrm{h}} \min -\max$ & $\lambda_{h}^{i}$ & $\mathrm{v}_{\mathrm{ph}}^{\mathrm{j}}$ \\
\hline Bamako (*) & 3.2 & 54.51 & 33 & $\begin{array}{l}1.84(1.44 ; \\
2.16)\end{array}$ & $\begin{array}{l}20.50(16.10 \\
24.10)\end{array}$ & $\begin{array}{l}0.82(0.76 ; \\
0.90)\end{array}$ & $\begin{array}{l}30.56(25.28 \\
38.89)\end{array}$ & $1.40-2.10$ & $\begin{array}{l}650(450 \\
1200)\end{array}$ & $\begin{array}{l}6.57 \text { (5.16; } \\
9.15)\end{array}$ \\
\hline Niamey & 3.4 & 51.31 & 84 & $\begin{array}{l}1.69(1.34 ; \\
2.25)\end{array}$ & $\begin{array}{l}17.75(12.30 \\
22.20)\end{array}$ & $\begin{array}{l}0.83(0.74 ; \\
0.89)\end{array}$ & $\begin{array}{l}33.33(24.44 ; \\
38.89)\end{array}$ & $1.40-2.10$ & $\begin{array}{l}860(490 \\
1400)\end{array}$ & $\begin{array}{l}8.08 \text { (5.60; } \\
9.63)\end{array}$ \\
\hline Dakar & 3.7 & 47.15 & 57 & $\begin{array}{l}1.70(1.38 ; \\
2.05)\end{array}$ & $\begin{array}{l}13.30(8.40 \\
18.80)\end{array}$ & $\begin{array}{l}0.80(0.71 ; \\
0.86)\end{array}$ & $\begin{array}{l}27.78(32.78 \\
33.33)\end{array}$ & $1.40-2.10$ & $\begin{array}{l}660(500 \\
1000)\end{array}$ & $\begin{array}{l}7.96(5.65 ; \\
9.14)\end{array}$ \\
\hline Agadez & 4.2 & 41.53 & 92 & $\begin{array}{l}1.64(1.38 ; \\
2.14)\end{array}$ & $\begin{array}{l}14.50(8.50 \\
20.30)\end{array}$ & $\begin{array}{l}0.84(0.71 ; \\
0.91)\end{array}$ & $\begin{array}{l}25.28(19.44 ; \\
30.56)\end{array}$ & $1.40-2.10$ & $\begin{array}{l}650(430 \\
1000)\end{array}$ & $\begin{array}{l}8.06(5.75 ; \\
9.61)\end{array}$ \\
\hline
\end{tabular}

In brackets the first and third quartiles respectively. Values are derived from AMMA Radio soundings. (*) = median values for July to September 2006

${ }^{\text {a }} f$ is the inertial frequency $\left(1 \times 10^{-5} \mathrm{rad} \mathrm{s}^{-1}\right)$

b $\mathrm{T}_{\text {inertial }}$ is the inertial period (h)

c $\mathrm{N}$ is the number of profiles use to derive the parameters

d $\omega^{*} / \mathrm{f}$ is the ratio of the intrinsic frequency to the inertial frequency

${ }^{\text {e }} \mathrm{E}_{\mathrm{T}}$ is the total energy density $\left(\mathrm{J} \mathrm{kg}^{-1}\right)$

${ }^{\mathrm{f}}$ Fup is the fraction of wave upward propagating energy

$\mathrm{g} \mathrm{T}$ is the period (h)

$\mathrm{h} \lambda_{\mathrm{v}}$ is the vertical wavelength $(\mathrm{km})$

i $\lambda_{\mathrm{h}}$ is the horizontal wavelength $(\mathrm{km})$

${ }^{\mathrm{j}} \mathrm{v}_{\mathrm{ph}}$ is the horizontal phase speed $\left(\mathrm{m} \mathrm{s}^{-1}\right)$

transitional and Sahelian phases over the area (Plougonven et al. 2003). The diurnal circulation cycle and/or the diurnal WAHL motion might generate "intermittent" mountain waves (Lothon et al. 2008; Lavaysse et al. 2009) because if the incident wind on the mountain range is not stationary the mountain waves are observed like "propagating" and intermittent waves (Caccia et al. 1997).

The annual variation of wave energy densities is consistent and connected in time with the annual variation of the WAM. From the results obtained in the 4 tropical stations, we conclude that the annual variation of $E_{T}$ is very similar all over the following tropical rectangle-like zone, $13^{\circ}-17^{\circ} \mathrm{N}$ latitude, $8^{\circ} \mathrm{E}-17.50^{\circ} \mathrm{W}$ longitude. Indeed, maximum wave activity is in July and August while the monsoon is over the tropical West Africa during the Sahelian phase. A relatively abrupt variation is observed during the monsoon onset due to an abrupt shift of the ITCZ whose date may fluctuate from one year to another around June 24 by 8 days (Sultan and Janicot 2003). After September, the ITCZ and the WAHL move towards the equator to be located over the Gulf of Guinea and at $20^{\circ}-30^{\circ} \mathrm{E}$, respectively. The slow monsoon retreat from September explains the decrease of wave activity to low values to October.

\subsubsection{Wave spectral parameters}

Spectral characteristics of dominant GWs are computed for each profile from May to September in the LS at the altitude range of $19-23 \mathrm{~km}$ above for the 4 tropical sites.

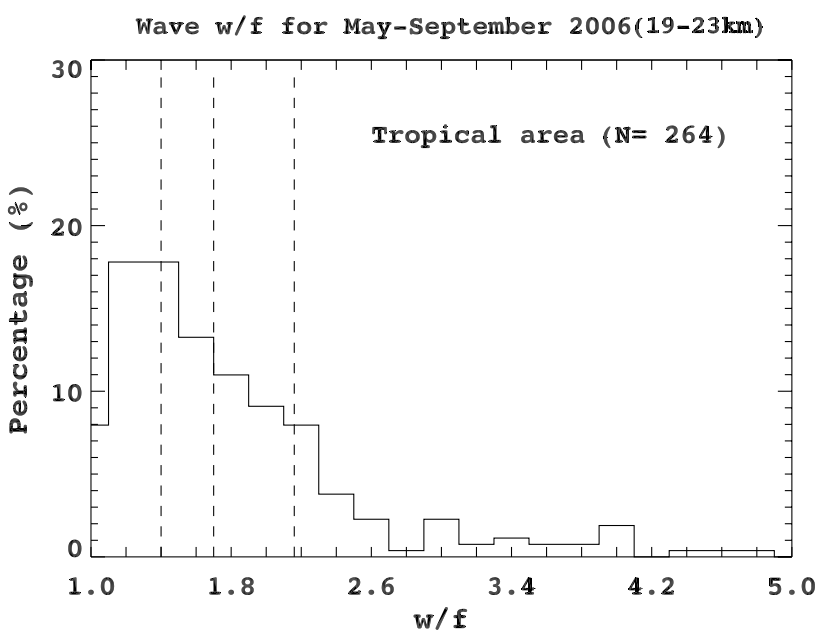

Fig. 6 Daily values of wave w/f derived from AMMA Campaign Radiosonde observations in West African tropical LS for the four tropical stations. $N$ indicates the total number of profiles used for the computation. The dashed vertical lines indicate the first, second and third quartiles

Median values are gathered in Table 4 for individual stations. The wave energy densities being similar for all the 4 West Africa tropical stations, so histograms of the spectral characteristics are computed with all the data (Figs. 6, 7, 8). GWs with short dominant vertical wavelengths, around $2.1 \mathrm{~km}$, are observed above tropical LS.

$\omega * / f$ ratios range between 1.1 and 2.2 for more than $75 \%$ of the observations with a maximum of occurrences 


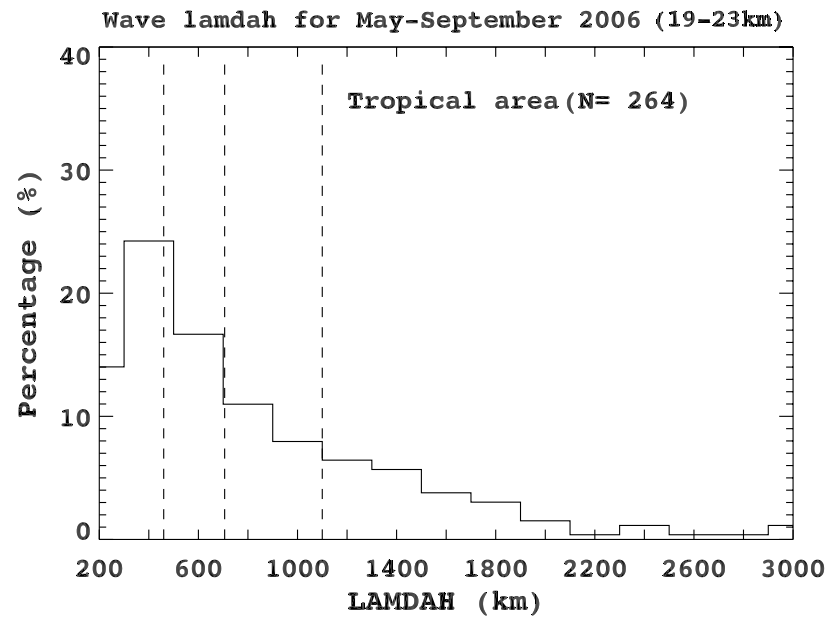

Fig. 7 The same as Fig. 6 but for horizontal wavelengths

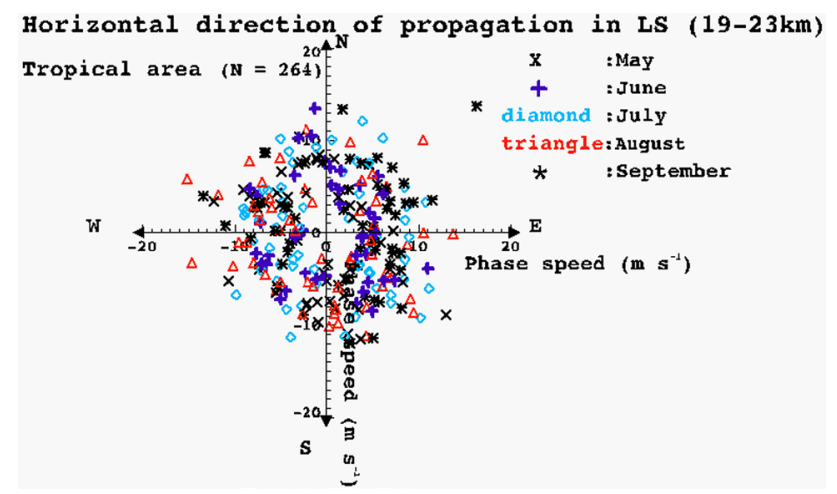

Fig. 8 Daily values of wave horizontal direction of propagation derived from AMMA Campaign Radiosonde observations in West African tropical LS for the four tropical stations. $\mathrm{N}$ indicates the total number of profiles used for the computation

in-between 1.1 and 1.5 and median value around 1.7 (Fig. 6) which corresponds to median period values of $24.43 \mathrm{~h}$ (1.02 days) at Agadez, $27.74 \mathrm{~h}$ (1.16 days) at Dakar, $30.18 \mathrm{~h}$ (1.26 days) at Niamey and $32.07 \mathrm{~h}$ (1.34 days) at Bamako. In the latitude range of $13.5^{\circ}-17^{\circ} \mathrm{N}$, the observed periods vary in the range 20-39 $\mathrm{h}$ (Table 4). The number of observed cases is lower for Bamako because only high resolution data are available from July to September during AMMA. Few profiles are available in June and July at Dakar.

Horizontal wavelengths range between 200 and $2000 \mathrm{~km}$ with maximum of occurrences for 300-700 km. Figure 7 provides a median horizontal wavelength around $720 \mathrm{~km}$ with $75 \%$ being less than $1100 \mathrm{~km}$. Median value of the stations vary between 650 and $860 \mathrm{~km}$ (Table 4)

All the observed waves are propagating upward from the troposphere, Fup $>79 \%$, (Tables 4, 6) with shallow angles to the horizontal as suggested by the ratio between vertical and horizontal wavelengths. Figure 8 points out horizontal directions of wave propagation, observed above the tropical area during the monsoon period, distributed in all the directions that imply distributed sources localized in random places in the monsoon zone. The median phase speed is less than $10 \mathrm{~m} \mathrm{~s}^{-1}$ with a median value around $8 \mathrm{~m} \mathrm{~s}^{-1}$ (Tables 4 and 6). As a matter of fact, the most probable sources are mesoscale convective systems, distributed all over West Africa (Janicot et al. 2008).

The anti-correlation between OLR and wave energy density, $\mathrm{E}_{\mathrm{T}}$, supports that convection as the main source of short vertical scale waves. The quasi-isotropic distribution of horizontal propagation directions shows that no specific filtering is globally observed in the upper troposphere and/ or LS but it is not excluded that some individual waves are filtered or damped. The method of median provides dominant horizontal phase speeds with intensity $<10 \mathrm{~m} \mathrm{~s}^{-1}$.

\subsubsection{Concluding remarks}

4.1.3.1 Main results In 2006, significant annual variations of the wave energy density are well correlated with the annual cycle of the WAM. Deep convection is the major source of such waves during the WAM period. Wave activity of short vertical wavelengths, less than $4 \mathrm{~km}$, shows a maximum during July and August when the WAM is installed over the tropical West Africa. Wave spectral parameters confirm, as it is suggested by ratios KE/PE, that the major wave contribution is IGWs with vertical and horizontal scales of 1.4-2.2 km and 450-1100 km respectively. Their intrinsic frequencies, $\omega^{*}$, in-between 1.1 and $2.2 \mathrm{f}$ or periods $<2$ days are observed in the tropical LS. Most of IGW energy propagates upward from the troposphere. The nearly isotropic distribution of horizontal directions of propagation means that no global background filtering of GWs is observed and supports convective wave sources well geographically distributed.

In the range of short vertical wavelengths, the major contributor of the total wave energy is the kinetic energy density, KE, which is revealed to be a good proxy of IGWs; $P E$ presents no substantial variation in the presence of those waves. This behaviour seems to be characteristic of such waves whatever the latitudes (Hertzog et al. 2002). As a consequence in this range of short vertical wavelengths and frequencies, $\mathrm{E}_{\mathrm{T}}$ cannot be re-constructed only from $\mathrm{PE}$ i.e. temperature observations because $\mathrm{PE}$ by itself cannot provide information on the seasonal wave variation. The estimates of $\mathrm{E}_{\mathrm{T}}, \mathrm{KE}$ and PE for 9 years (2001-2009) will help to determine whether 2006 WAM with large $p$ values is representative of tropical African wave activity or is a specific case. 
4.1.3.2 Intercomparison with other observations Wave parameters of this study agree with similar observations in southern tropical hemisphere above Cocos Island $\left(12^{\circ} \mathrm{S}\right.$, $97^{\circ} \mathrm{E}$ ) (Vincent and Alexander 2000). The authors compute $\mathrm{PE}$ and $\mathrm{KE}$ and average them over a 6-year period. Thus mean values are not comparable with the ones obtained in this study, due to the large variation of $\mathrm{E}_{\mathrm{T}}$ and $\mathrm{KE}$ during WAM period. Vincent and Alexander (2000) find a dominance of eastward propagating waves above Coco Island where strong convection occurs at all times of the year.

Tsuda et al. (2004) carried out a radiosonde campaign, DAWEX, from October to December 2001 in the Darwin area; the launch sites being located on Melville Island $\left(11.4^{\circ} \mathrm{S}, 130.3^{\circ} \mathrm{E}\right)$, on Darwin Airport $\left(12.4^{\circ} \mathrm{S}, 130.9^{\circ} \mathrm{E}\right)$ and on Katerine civilian airport $\left(14.5^{\circ} \mathrm{S}, 132.5^{\circ} \mathrm{E}\right)$. KE values are smaller in the layer, $20-25 \mathrm{~km}$, of westward winds, around $20 \mathrm{~m} / \mathrm{s}$ due to the QBO, than above $25 \mathrm{~km}$ or below $20 \mathrm{~km}$. The peak of KE above altitudes of $25 \mathrm{~km}$ coincides with the peak of eastward wind shear. In this study even if there are still westward winds, the eastward wind shear is present in the altitudes of $19-23 \mathrm{~km}$ that may explain that high KE values are observed.

Above Gadanki $\left(13.5^{\circ} \mathrm{N}, 79.2^{\circ} \mathrm{E}\right)$, the maximum in $\mathrm{GW}$ energy observed in the LS during Indian monsoon is attributed to the strong eastward shear (Ratnam et al. 2008; Nath et al. 2009).

PE values are also obtained from CHAMP/GPS radio occultation (Ratnam et al. 2004). A main difference is the vertical scale selected $10 \mathrm{~km}$ versus $4 \mathrm{~km}$ in this study. Then their results include both GWs and planetary waves. Over West Africa, the authors find large PE values in March and in December; those PE maxima correspond nor to our observations neither to expected seasonal variations of GWs related to deep convection, occurring in summer during the WAM. The $10 \mathrm{~km}$ vertical scale does not filter synoptic waves that may have large temperature fluctuations and PE observations may lead to biased wave energy, as shown in this study.

\subsection{Equatorial region}

In the equatorial LS the E-phase QBO (descending easterly wind) is at its end (Fig. 3b). The shift to the W-phase (eastward winds) occurs in June and February at 19 and at $23 \mathrm{~km}$ respectively. Eastward shear is present during the period. The present study uses AMMA radiosonde observations over two equatorial sites: Douala and Abidjan.

Douala $\left(4.1^{\circ} \mathrm{N}, 9.45^{\circ} \mathrm{E}\right)$ is located in a wet equatorial zone in the gulf of Guinea at $30 \mathrm{~km}$ from the sea and near the forest. Its climate is characterized by two main seasons but four distinct periods can be distinguished during the year. The "less wet season" occurs from mid-November to the end of February (monthly precipitations spread between
140 and $50 \mathrm{~mm}$ ). From March to the end of June, it is the period of large storms. March and April are the hottest period, tornadoes and squall lines multiply when monsoon pushes back towards North the continental air. From the end of June to mid-October, the true/real rain season takes place; July, August and September are the rainiest months (more than $700 \mathrm{~mm}$ per month). From mid-October to midNovember, a transition period is observed during which the large rains are spaced.

Abidjan $\left(5.25^{\circ} \mathrm{N}, 3.94^{\circ} \mathrm{W}\right)$ is located in the south of Côte d'Ivoire, in the Gulf of Guinea and is crossed by the Ébrié lagoon. The climate is of subequatorial type (i.e. hot and wet) and is characterized by low amplitudes temperatures (the monthly mean maximum is $31{ }^{\circ} \mathrm{C}$-from November to May and the monthly mean minimum is $22^{\circ} \mathrm{C}$-in August and September), a strong moisture (which reaches $80 \%$ ) and abundant precipitations (around $2000 \mathrm{~mm}$ in the year). Four seasons are observed: a dry and hot season from December to April during which some rains are observed $(\sim 26 \mathrm{~mm})$; a season of large rains from May to July (maximum of precipitations occurred in June $\sim 610 \mathrm{~mm}$ ); a short dry season from August to September; a short season of rains from October to November (monthly mean precipitations is $\sim 150 \mathrm{~mm}$ ).

In Douala, the AMMA data are available from March 2006 until September 2006, however the Wyoming data are available all over the year. In Abidjan, only AMMA data are available during few months, July until September.

\subsubsection{Wave energy densities}

Figure 9 shows seasonal variation of the OLR, PE, KE and $\mathrm{E}_{\mathrm{T}}$ above Douala. In regards to the tropical sites, the number of selected profiles per month is smaller which might produce some biases on energy density values. Monthly variations are different from the tropical ones. OLR is less than $250 \mathrm{~W} \mathrm{~m}^{-2}$ all over the year, except in December, and presents two minima around $200 \mathrm{~W} \mathrm{~m}^{-2}$, in April and September. The equatorial annual cycle of $\mathrm{E}_{\mathrm{T}}$ above Doula shows evidence of strong values greater than $12 \mathrm{~J} \mathrm{~kg}^{-1}$ from January to August. $\mathrm{E}_{\mathrm{T}}$ maximum value, related to the first OLR minimum, is observed in May with a magnitude of $25.2 \pm 5.3 \mathrm{~J} \mathrm{~kg}^{-1}$. Then $\mathrm{E}_{\mathrm{T}}$ decreases after May. The number of data in August is 4 and makes its value not reliable, also in comparison with the value, $10 \mathrm{~J} \mathrm{~kg}^{-1}$, obtained with more data, 11 instead of 4 , from the Wyoming upperair database. The secondary peak, related to the other OLR minimum, is localized in September at both Douala and Abidjan sites. From October to December, $\mathrm{E}_{\mathrm{T}}$ values are around $8-9 \mathrm{~J} \mathrm{~kg}^{-1}$.

OLR values are of similar magnitudes in May and September $\left(210\right.$ and $\left.200 \mathrm{~W} \mathrm{~m}^{-2}\right)$, respectively while there is a large difference of $\mathrm{E}_{\mathrm{T}}$ magnitude in May and September. 

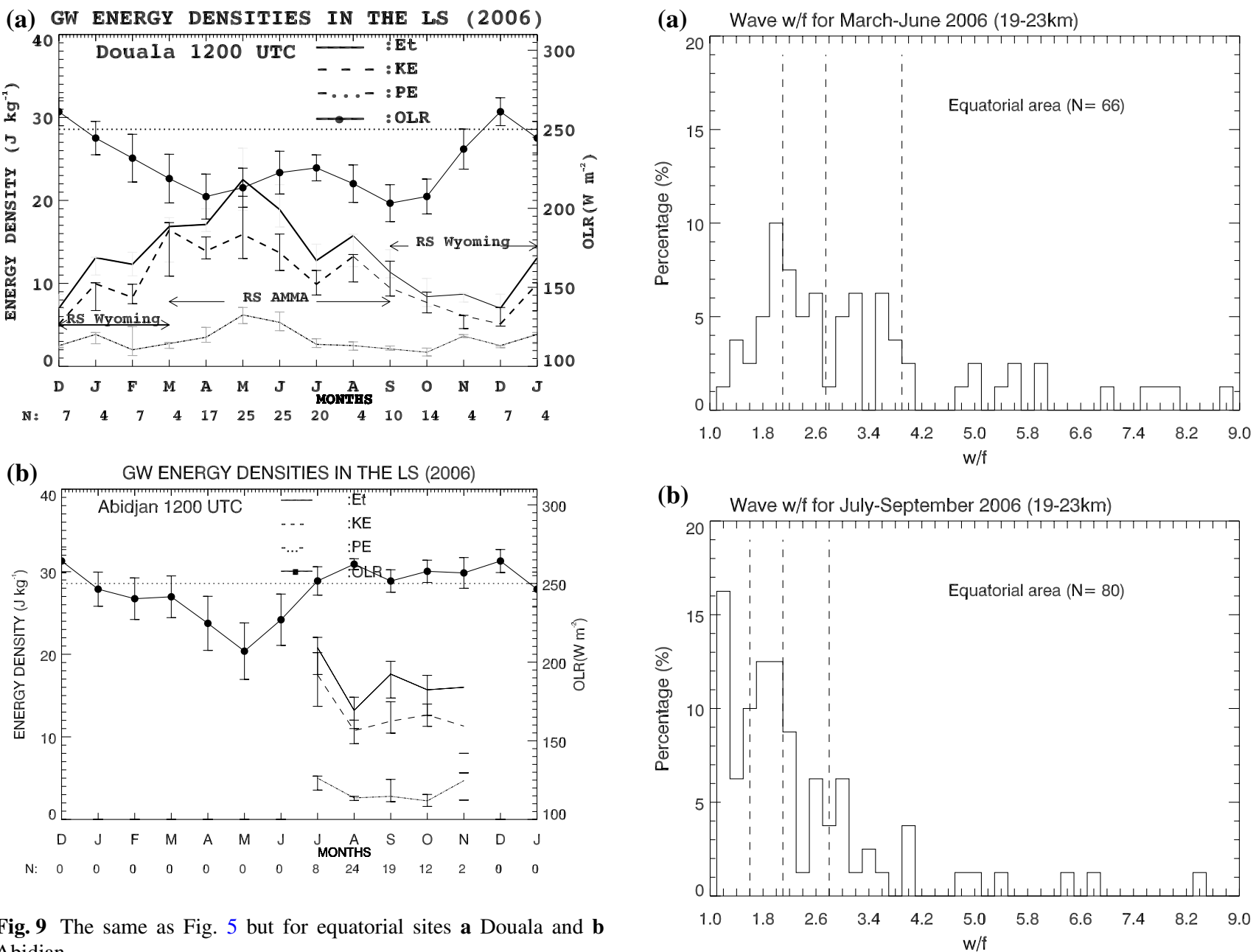

Fig. 9 The same as Fig. 5 but for equatorial sites a Douala and b Abidjan

The second peak intensity is around half the intensity of the maximum in May in Douala. KE is the major contributor of the total energy density and PE has small values.

During the oceanic phase, when the OLR starts to be lower than $250 \mathrm{~W} \mathrm{~m}^{-2}$, from January to April $\mathrm{E}_{\mathrm{T}}$ is around $14 \mathrm{~J} \mathrm{~kg}^{-1}$, PE being around $3 \mathrm{~J} \mathrm{~kg}^{-1}$. Wave activity becomes to be noticeable and might be produced by the "convective" ocean or during intrusions of rain and convection from the ocean onto the continent associated to surface wind accelerations (Leduc-Leballeur et al. 2011). Then the period, mid-April to June, corresponds to the coastal phase i.e. the rain belt located around $4^{\circ} \mathrm{N}$. A maximum of $\mathrm{E}_{\mathrm{T}}$ around $25 \mathrm{~J} \mathrm{~kg}^{-1}$ is observed in May. PE and $\mathrm{KE}$ show evident similar variation as opposed to observations above tropical sites. During this first maximum PE values increase and attain up to $7 \mathrm{~J} \mathrm{~kg}^{-1}\left(6.7 \pm 0.8 \mathrm{~J} \mathrm{~kg}^{-1}\right)$ in May co-localized with the peak of $\mathrm{E}_{\mathrm{T}}$ and $\mathrm{KE}$. The contribution of $\mathrm{KE}$ to $\mathrm{E}_{\mathrm{T}}$ is less than $75 \%$, and the ratio $p=\mathrm{KE} / \mathrm{PE}$ is around 1.5-2 from February to June, as expected from the GW spectrum. At the second peak, PE does not follow the $\mathrm{KE}$ variations and is small around $2-3 \mathrm{~J} \mathrm{~kg}^{-1}$. The ratio

Fig. 10 Daily values of wave w/f derived from AMMA Campaign Radiosonde observations in West African tropical LS for the equatorial area. a for March to June; $\mathbf{b}$ for July to September. $\mathrm{N}$ indicates the total number of profiles used for the computation. The dashed vertical lines indicate the first, second and third quartiles

$\mathrm{KE} / \mathrm{PE}$ is greater than 2.2 and attains 3.4 in October. This situation looks like the tropical situation. This period, July to October corresponds to the Sahelian phase i.e. WAM and the retreat phase of the ITCZ towards the Gulf of Guinea. For Abidjan (from July to October) PE is similar to Douala and fluctuates between 2 and $4 \mathrm{~J} \mathrm{~kg}^{-1}$ but the contribution of $\mathrm{KE}$ to $\mathrm{E}_{\mathrm{T}}$ is higher (around $80 \%$ ).

In equatorial region, mixed equatorial waves such as Kelvin and Rossby-GW with shorter vertical wavelength less than $5 \mathrm{~km}$, may contribute to energy densities. Indeed, Holton et al. (2001) observed in the range 20-25 km Kelvin waves with vertical wavelengths of 3-4.5 km corresponding to zonal wave number 4 above Nauru $\left(0.5^{\circ} \mathrm{S}, 166.9^{\circ} \mathrm{E}\right)$. Some tests have been done and only two cases in May might have the characteristics of Kelvin and mixed Rossby-GW relative to the expected characteristics of temperature, zonal 


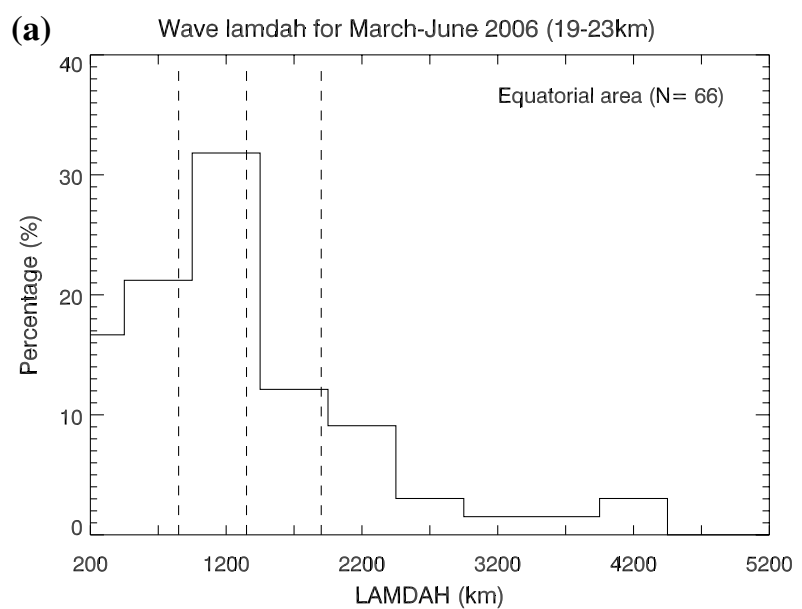

(b) Wave lamdah for July-September 2006 (19-23km)

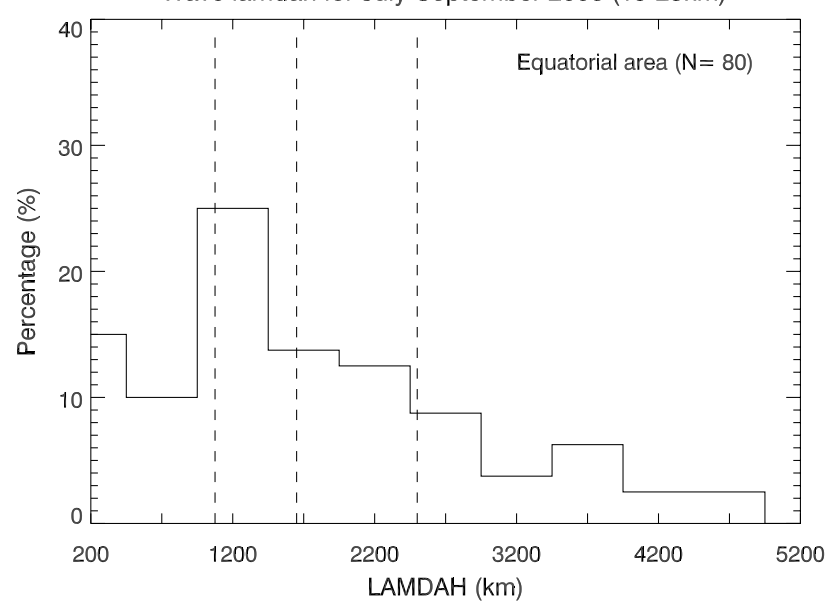

Fig. 11 The same as Fig. 10 but for horizontal wavelengths

and meridional wind perturbations (Holton 1992). Further studies in combination with satellite data will be performed.

\subsubsection{Wave parameters at Douala (March-June 2006)}

GW spectral parameters are computed from available radiosonde data in equatorial area during the WAM. Data at Abidjan are available for 3 months (July-September) and from March to September at Douala.

Assuming GW polarization relationships, Figs. 10 and 11 show occurrences of daily wave-spectral parameters for the equatorial area and Tables 5 and 6 provide the corresponding median values. Figure 10a presents histogram of the ratio $\omega^{*} / \mathrm{f}$ during the March-June period. The intrinsic frequencies, $\omega^{*}$, vary between $1.4 \mathrm{f}(147.8 \mathrm{~h}$ or 6.2 days $)$ to $4 \mathrm{f}$ ( $43.6 \mathrm{~h}$ or 1.8 days) for around $80 \%$ of the observations with a median value at $2.75 \mathrm{f}$ ( $63.4 \mathrm{~h}$ or 2.6 days). Maximum period occurrences are between 1.8 and 6.2 days. The vertical wavelength is around $2.1 \mathrm{~km}$. 
(a)

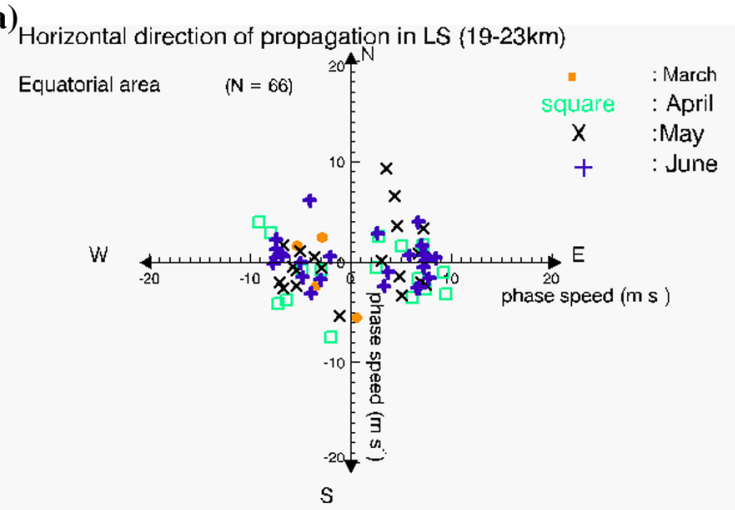

(b)

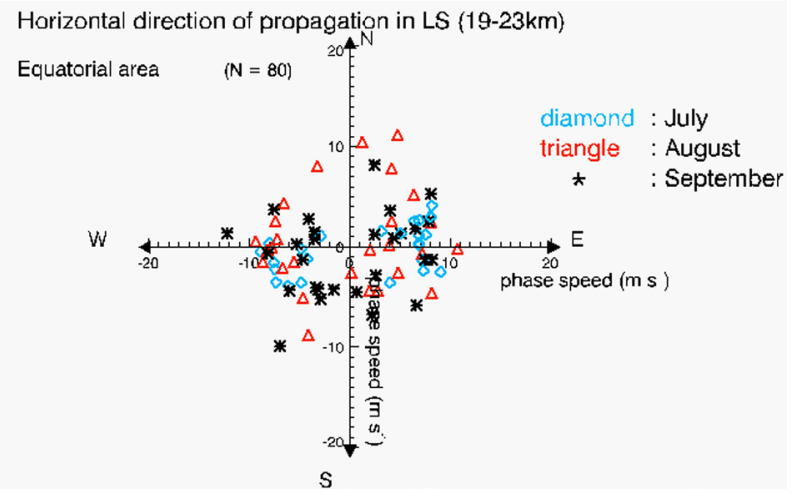

Fig. 12 The same as Fig. 8 but for the equatorial region a for March to June and $\mathbf{b}$ for July to September

Figure 11 (March-June) shows horizontal wavelengths ranging between 200 and $2200 \mathrm{~km}$ i.e. $90 \%$ of the observations with a median value of $1300 \mathrm{~km}$. The fraction of upward energy fluxes is around 0.69 (median value) with a large dispersion in-between 0.58 and 0.8. During March to June, waves are found to propagate quasi-zonally, in eastward or westward zonal directions $(42.4 \%$ in eastward direction and $43.9 \%$ in westward direction) (Fig. 12a) with a median phase velocity around $7 \mathrm{~m} \mathrm{~s}^{-1}$.

The ratio KE/PE in-between 1.5 and 2 corresponds to the expected value assuming GW total energy spectrum scaling at $\omega^{-5 / 3}$.

\subsubsection{Wave parameters in Abidjan and Douala (July- September 2006)}

From July to September, the behaviour looks like the tropical one with large KE/PE ratio. Over the equatorial area the median value of the intrinsic frequency for the dominant mode is $1.9 \mathrm{f}$ with frequency in the range of 1.2 and $3.8 \mathrm{f}$ (Fig. 10b). Frequency median values are around 2 for Abidjan and 2.2 for Douala (Table 5). Dominant periods of waves range between $50 \mathrm{~h}$ ( 1 days) and $86.11 \mathrm{~h}$ (4.6 days) 
at Abidjan and, $80.6 \mathrm{~h}$ (3.35 days) and $145.3 \mathrm{~h}$ (6 days) at Douala. The horizontal wavelength has a median value around $1500 \mathrm{~km}$ for Abidjan and $1800 \mathrm{~km}$ for Douala with a large range $200 \mathrm{~km}$ to $3200 \mathrm{~km}, 88 \%$ of the observations (Table 5) and $1650 \mathrm{~km}$ for all data (Fig. 11b).

From July to September directions of propagation seems to be distributed in all the directions but a more pronounced quasi-zonally propagation is prominent (Fig. 12b). Over Abidjan, in August directions of propagation are distributed in all the directions (figure not shown) and in September directions of propagation are quasi-zonally with a southward component; and with both northward and southward over Douala. In July, August and September the differences observed between Abidjan and Douala, especially for the wave directions of propagation may be due to their geographical situations relatively to the WAM location and their climatology; the ocean being South to Abidjan, and West to Douala; August and September being dry in Abidjan and still rainy in Douala.

The fraction of upward energy is 0.73 (median value) for Douala and 0.79 (median value) with a dispersion, 0.01 for Douala and 0.09 for Abidjan. These support that wave sources are mostly located in the troposphere. In comparison with observations in the tropical area, waves are observed in a larger range of periods due to the inertial periods and of horizontal wavelengths. Horizontal phase speeds are similar to tropical area whereas period and horizontal wavelength are longer than tropical ones. Indeed inertial periods are larger in the equatorial region than in the tropics. These are consistent with the presence of convective structures of 3-8 day periods (Fig. 4b).

\subsubsection{Concluding remarks}

4.2.4.1 Main results In 2006 two strong periods of convection are observed at equatorial sites related to the annual cycle of the WAM. They are accompanied with wave activity of short vertical scale waves. Short vertical scale waves have a strong activity during the first period i.e. during the coastal phase of the WAM peaking in May. A second peak of half intensity is observed in August-September during the transitional phase from the Sahelian to the oceanic phases.

During the coastal phase, March to June, IGWs with vertical and horizontal scales of $1.4-2.1 \mathrm{~km}$ and 830 $1900 \mathrm{~km}$ with $1300 \mathrm{~km}$ the median value respectively and, the intrinsic frequencies, $\omega^{*}$, in-between 1.4 and $4 \mathrm{f}$ or periods $<6.2$ days are observed in the equatorial LS. Around $69 \% \mathrm{GW}$ energy propagates upward from the troposphere. The distribution of horizontal directions of propagation is mainly zonal.

During the Sahelian phase, July to September, IGWs with vertical and horizontal scales of $1.4-2.1 \mathrm{~km}$ and $1100-2700 \mathrm{~km}$ with $1650 \mathrm{~km}$ the median value respectively and, the intrinsic frequencies, $\omega^{*}$, in-between 1.2 and $3 \mathrm{f}$ or periods $<6.2$ days are observed in the equatorial LS. Around $76 \% \mathrm{GW}$ energy propagates upward from the troposphere. The distribution of horizontal directions of propagation differs from Abidjan to Douala due the difference in geographical location.

Both PE and KE are good indicators of short vertical scalewave activity during the coastal phase as opposed to the second period for which $\mathrm{E}_{\mathrm{T}}$ is mainly kinetic. Over Douala from May to July, horizontal direction of propagation is mostly distributed quasi-zonally. A large spectrum of horizontal wavelengths and periods are obtained. The clear identification of two cases of mixed equatorial waves suggests a possible contribution but minor of such waves in the analyzed equatorial wave energy densities.

In July, August and September, short vertical scale wave activity above Abidjan and Douala (only for July and September) is mainly produced by IGWs similar as observations above tropical stations but with larger horizontal wavelength i.e. several thousand $\mathrm{km}$ instead of several $100 \mathrm{~km}$. There is also an energy enhancement of the spectrum at near-inertial frequencies.

4.2.4.2 Intercomparison with other observations Vincent and Alexander (2000) noted similar difference in GW horizontal wavelengths at tropical and equatorial stations. Other observations with radiosondes were carried out in lower latitudes $7^{\circ} \mathrm{S}$ in Indonesia (Tsuda et al. 1994b) and $10^{\circ} \mathrm{S}$ at Santa Cruz during TOGA/COARE (Karoly et al. 1996). Vertical wavelengths vary in the same range around $2-3 \mathrm{~km}$; and horizontal wavelengths also range between 1000 and $2000 \mathrm{~km}$ Indonesia (Tsuda et al. 1994b).

\subsection{Tropical and equatorial momentum fluxes}

Covariances u' $\mathrm{T}^{\prime}{ }_{+90^{\circ}}$ and $\mathrm{v}^{\prime} \mathrm{T}^{\prime}{ }_{+90^{\circ}}$ have been used to determine vertical fluxes of wave zonal and meridional momentum (Eq. 5) (Vincent et al. 1997; Vincent and Alexander 2000).

$\left.\begin{array}{l}\overline{u^{\prime} w^{\prime}}=-\frac{\omega^{*} \cdot g}{N^{2}} \cdot \overline{u^{\prime} \widehat{T}_{+90}^{\prime}} \cdot \delta_{-}\left(\omega^{*}\right) \\ \overline{v^{\prime} w^{\prime}}=-\frac{\omega^{*} \cdot g}{N^{2}} \cdot \overline{v^{\prime} \widehat{T}_{+90}^{\prime}} \cdot \delta_{-}\left(\omega^{*}\right)\end{array}\right\}$

where $\delta_{-}\left(\omega^{*}\right)=\left(1-\frac{f^{2}}{\omega^{* 2}}\right), f$ is the inertial frequency, $\omega^{*}$ the angular intrinsic frequency, $\hat{T}^{\prime}=\frac{T^{\prime}}{\bar{T}}$ the normalized temperature perturbation, u' and v' are zonal and meridional wind perturbation respectively, $g$ is the gravitational constant, $N$ is the buoyancy frequency and $\mathrm{T}^{\prime}{ }_{+90^{\circ}}$ is the value of temperature perturbation after shifting phase by $+90^{\circ}$ via Hilbert Transform. 

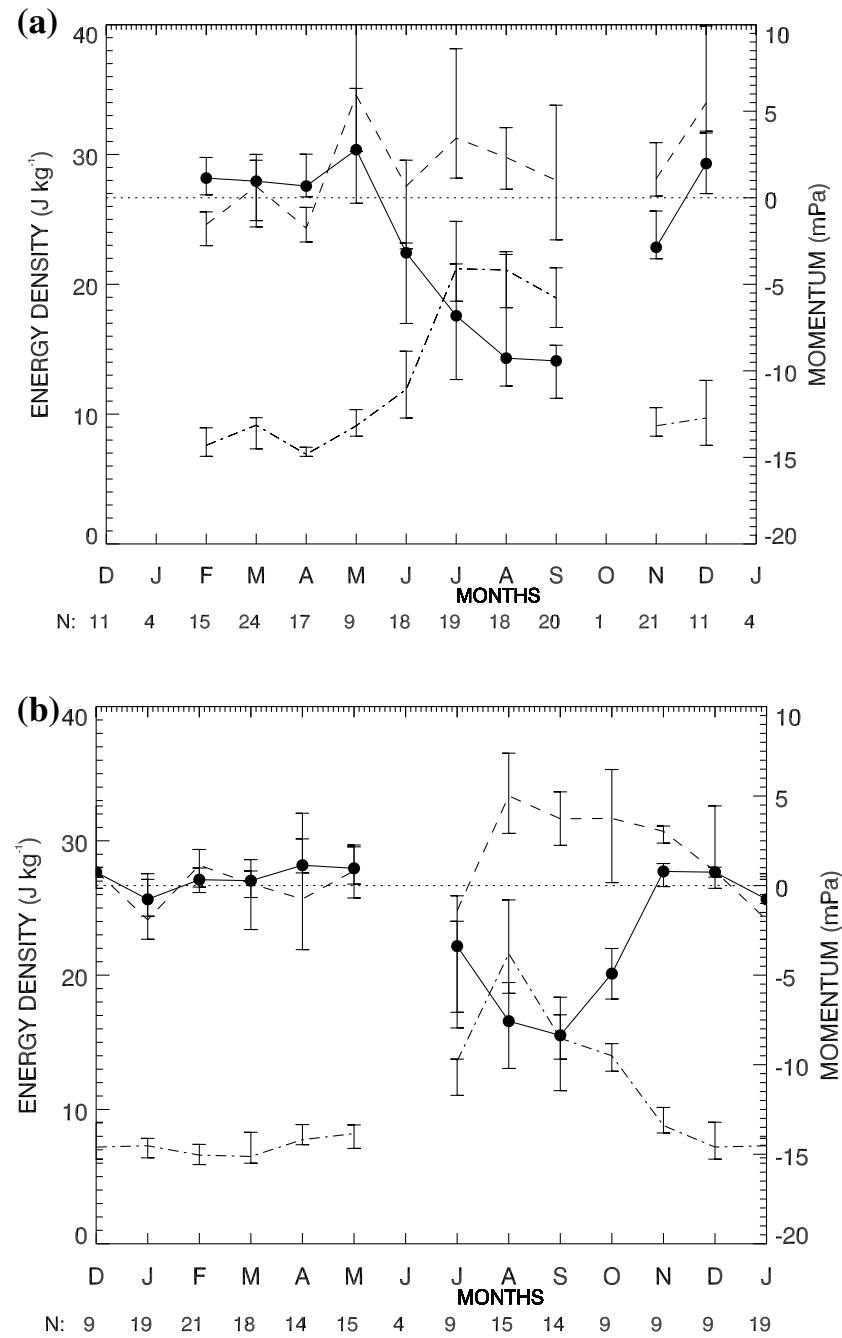

Fig. 132006 annual cycle of GW energy densities monthly median values (left hand ordinate) and vertical flux of horizontal momentum components (right hand ordinate) in the West African LS for a Niamey, b Dakar, c Agadez and d Douala. $\mathrm{N}$ indicates the number

Finally, taking into account the atmosphere density $\rho_{0}$, the zonal momentum is defined as $\overline{\rho_{0}} \overline{u^{\prime} w^{\prime}}$. Vertical flux of meridional momentum $\left(\overline{\rho_{0}} \overline{\mathrm{v}^{\prime} w^{\prime}}\right)$ is established in a similar manner. Overbars indicate an altitude average.

Daily height-averaged vertical fluxes of wave zonal and meridional momentum $\left(\overline{\rho_{0}} \overline{u^{\prime} w^{\prime}}\right.$ and $\overline{\rho_{0}} \overline{\mathrm{v}^{\prime} w^{\prime}}$ respectively) are derived from AMMA 2006.

\subsubsection{Results during WAM 2006}

Distributions of daily values of Fup and vertical fluxes of zonal momentum for 2006, show that the main vertical direction of zonal momentum flux propagation is upward (figure not shown). Above tropical sites, daily vertical fluxes of meridional momentum have weaker positive amplitudes as well as negative ones indicating both
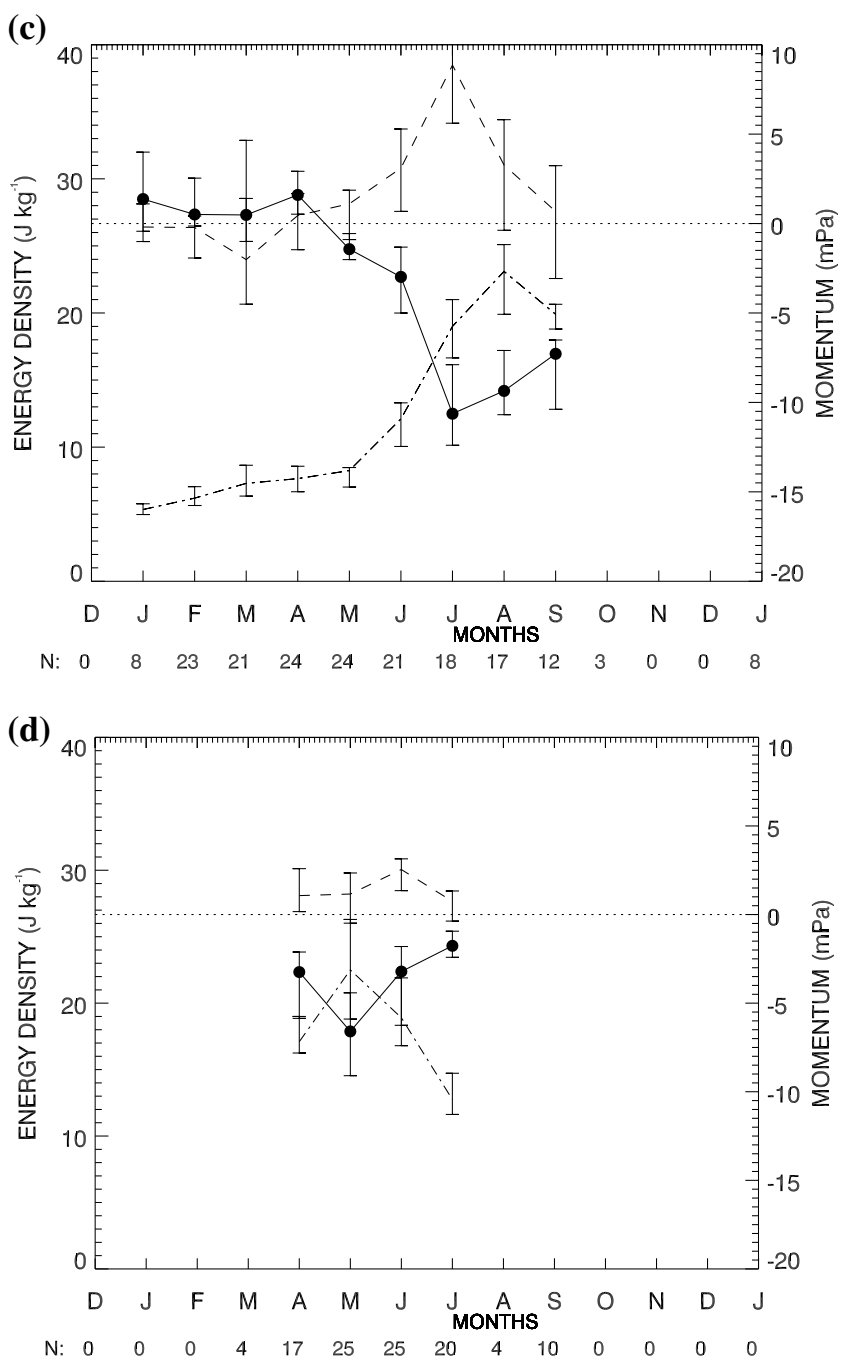

of profiles per month used for the computation. Dash dot line is $\mathrm{E}_{\mathrm{T}}$, black circles is the zonal momentum and dashed line is the meridional momentum

northward and southward direction of propagation. Above equatorial area (Douala), a nearly zero meridional momentum amplitude highlights that both northward and southward propagation are not extended as for tropical one (figure not shown).

The set of Fig. 13 shows the monthly median values of $\mathrm{E}_{\mathrm{T}}$ superimposed to the vertical flux of zonal and meridional momentum in the tropical and equatorial LS. Above tropical and equatorial stations, the period of maximum $\mathrm{E}_{\mathrm{T}}$ matches the one of maximum vertical flux of zonal momentum in absolute value.

Thus in the tropical region, a seasonal variation is observed for upward flux of zonal momentum. The upward flux of the westward momentum (negative values) is prevailing from May-June to October or November i.e. during the WAM with a magnitude ranging from $8.5 \mathrm{mPa}$ to 
$11 \mathrm{mPa}$. Upward flux of the eastward momentum occurs from January to April-May and after the WAM period i.e. after October-November. Its magnitude is less than $3.5 \mathrm{mPa}$, for all the sites. Over tropical region, an oscillation with weaker amplitude (around $2 \mathrm{mPa}$ ) of the upward flux of meridional momentum $\left(\overline{\rho_{0}} \overline{\mathrm{v}^{\prime} w^{\prime}}\right)$ from northwards (positive values) to southwards (negative values), is observed from January to April. Whereas upward flux of meridional momentum is different from one site to another, it is northwards with values between 2 and $8.5 \mathrm{mPa}$ and observed from May to September during the WAM (period of strong $\mathrm{E}_{\mathrm{T}}$ ).

In the equatorial area due to a lack of data and too small number of points in August and November, the seasonal variation of the zonal momentum cannot be determined for the equatorial region (Douala). The minimum of the upward flux of the westward momentum is localized in May with the magnitude of $6.5 \mathrm{mPa}$. Above equatorial area upward fluxes of meridional momentum are positive i.e. northwards and strongest magnitudes are around $3 \mathrm{mPa}$. Temporal behaviour doesn't exhibit a clear variation in relation with $\mathrm{E}_{\mathrm{T}}$ as indicated for tropical area because of lack of data and of too small number of points.

\subsubsection{Concluding remarks}

The absolute values of zonal momentum derived from our observations $(3.5-8.5 \mathrm{mPa})$ are higher than values derived from previous studies and are in relation with short period waves.

At Singapore $\left(1.4^{\circ} \mathrm{N} / 104^{\circ} \mathrm{E}\right)$ Sato and Dunkerton (1997) found from direct estimates for short period waves ( $<3$ days) zonal momentum of around $1.5 \mathrm{mPa}$ at $21 \mathrm{~km}$ during eastward and westward wind shear. In the tropics, Vincent and Alexander (2000) obtained in the altitude range $18-25 \mathrm{~km}$ a QBO-like variation of upward zonal fluxes with amplitude of about $1.5-2.5 \mathrm{mPa}$ for IGWs with 20-25 $\mathrm{h}$ period; the corresponding meridional momentum is positive and smaller in magnitude $(0.5 \mathrm{mPa})$. Zonal momentum of around $2 \mathrm{mPa}$ is derived from space instruments (Ern et al. 2004). Vincent and Alexander (2000) hypothesize that differences in momentum magnitudes can be due to factors such as geographic location, wave periods, height ranges covered and waves types involved and the appropriate choice of frequency to compute momentum fluxes.

During the WAM 2006, in the tropical LS, the distribution of dominant directions of horizontal propagation looks like quasi-isotropic with more or less the same number of eastward and westward propagating waves, 139 and 125 (cf. Figure 8). Convective structures are distributed in the entire tropical region leading to the presence of both eastward and westward momentum flux in the troposphere and in the LS. The westward momentum flux is prevailing with a maximum magnitude around $10 \mathrm{mPa}$. It means that the eastward propagating waves have less energy or are filtered in the troposphere.

Berès et al. (2002) found such a westward asymmetry and propose at least two factors: (1) the strength of the convection at the developing and mature stage of the storm and (2) the difference between the wind above the storm and the storm's motion. More detailed studies have to be carried out for the West Africa cases.

\section{Inter-annual variability of wave activity}

It was shown in part 1 that GWs play a coupling role from the troposphere to the LS. Thus they interact with the QBO, the main tropical and equatorial stratospheric feature. In this second part the inter-annual variability of wave activity is determined over 9 years, from January 2001 to December 2009 in West Africa. Indeed climate modeling needs long term observations and analyses to constrain and to validate models. Several previous studies reveal that peaks of wave energy density vary from year-to-year with a bi-annual periodicity in the LS (Sato et al. 1994; Vincent and Alexander 2000; Shimizu and Tsuda 2001; Zhang et al. 2012). Wave energy densities are calculated for Niamey and Douala respectively by using dataset from the WyomingUniversity Upper-air observation. Time series describe the inter-annual variability of energy densities and the QBO impact on low frequency GW activity. Because of its coarse vertical resolution $(300-\mathrm{m})$, the long-term dataset provides only energy densities, here examined.

\subsection{Tropical region}

\subsubsection{Inter-annual variability}

Annual and inter-annual variabilities are observed in the climatology of $\mathrm{E}_{\mathrm{T}}$ and $\mathrm{KE}$ above Niamey (Fig. 14a) with maximum values in June-September during the monsoon period and lower activity from October to April (dry season), as shown in Sect. 4.1.1. During the monsoon period, peak intensity varies from year-to-year between values higher than $18 \mathrm{~J} \mathrm{~kg}^{-1}$ and lower values in the range $10-14 \mathrm{~J} \mathrm{~kg}^{-1}$. PE varies little between 1 and $4 \mathrm{~J} \mathrm{~kg}^{-1}$.

For the years of high values of $E_{\mathrm{T}}$ i.e. 2002, 2004, 2006 and $2008, \mathrm{E}_{\mathrm{T}}$ variations above Niamey are drawn together on Fig. 15a. Similar behaviour is observed with large wave activity around $20 \mathrm{~J} \mathrm{~kg}^{-1}$ during the monsoon period. The ratio KE/PE is higher than 3. In contrast low values of $\mathrm{E}_{\mathrm{T}}$ ranged between 10 and $15 \mathrm{~J} \mathrm{~kg}^{-1}$ are observed in 2001, 2003, 2005, 2007 and 2009 (cf. Fig. 15b). For "odd" years there is no evidence of a common and characteristic 

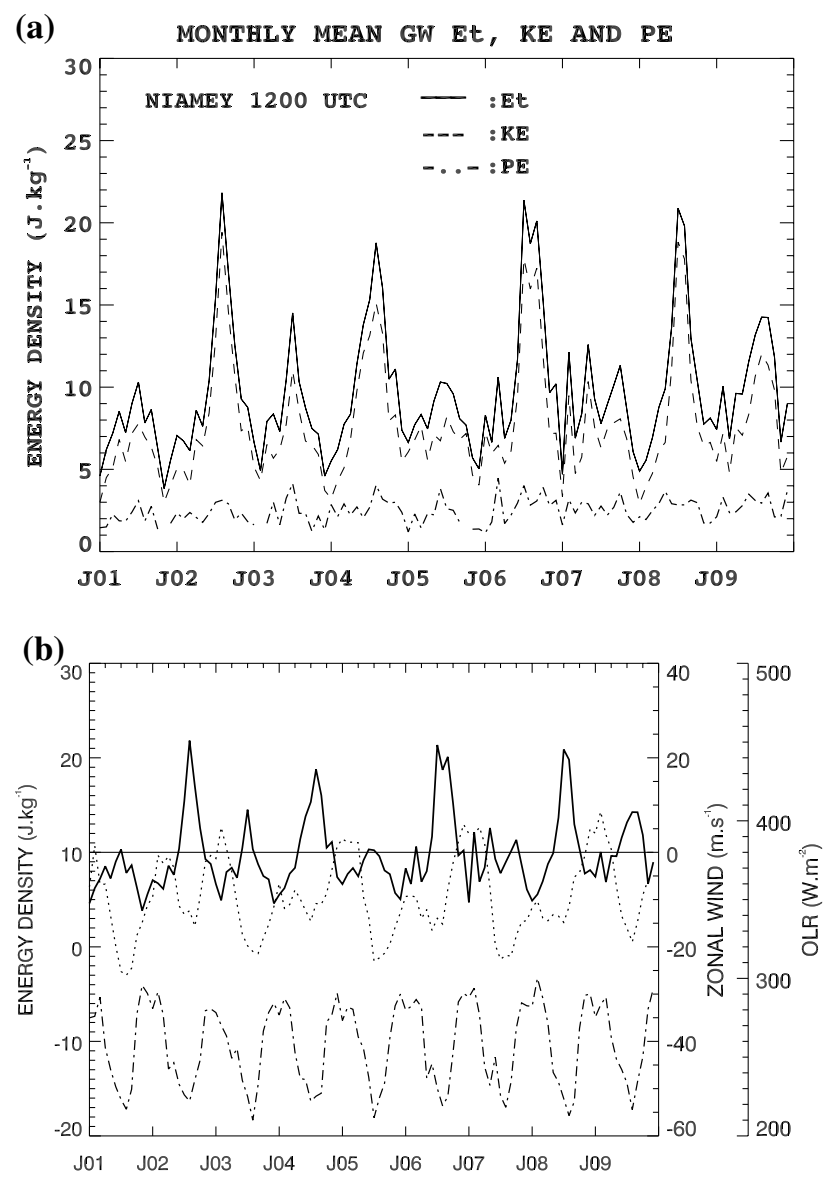

Fig. 14 a Time series of wave monthly mean energy densities in the lower stratosphere of Niamey for January 2001 to December 2009 computed with radiosonde data extracted from Wyoming University database. b Time series (January 2001 to December 2009) of wave monthly mean total energy density, mean zonal wind at $21 \mathrm{~km}$ altitude and OLR at Niamey. On a the solid line is $\mathrm{E}_{\mathrm{T}}$, the dashed line is $\mathrm{KE}$ and the dash dot dot is $\mathrm{PE}$; on $\mathbf{b}$ the solid line is $\mathrm{E}_{\mathrm{T}}$, the dotted line is the zonal wind and the dash dot dot is OLR

behaviour of wave activity except in 2009 with a small increase of $\mathrm{E}_{\mathrm{T}}$ during the whole WAM period (maximum in September). No such periodicity is observed neither in OLR data nor in precipitations (Janicot et al. 2008). In conclusion, $\mathrm{E}_{\mathrm{T}}$ maxima present a two-year variation of density values with maximum peaks during even years. They are not related to WAM proxies such as OLR and precipitation. Thus strong wave filtering is likely to occur during the "odd"-year WAM periods.

\subsubsection{Relationship with $Q B O$}

The QBO is observed in the equatorial and tropical LS (up to $25-27^{\circ} \mathrm{N}$ ) (Baldwin et al. 2001) as Fig. 3 shows. Figure $14 \mathrm{~b}$ presents variations of $\mathrm{E}_{\mathrm{T}}$, zonal wind at $21 \mathrm{~km}$ and OLR. In 2006 like in 2002, 2004 and 2008, zonal wind at $21 \mathrm{~km}$ is westwards with an amplitude around $10 \mathrm{~m} \mathrm{~s}^{-1}$ (a) NIAMEY (1200 UTC) MONTHLY MEAN Et in LS $(19-23 \mathrm{~km})$

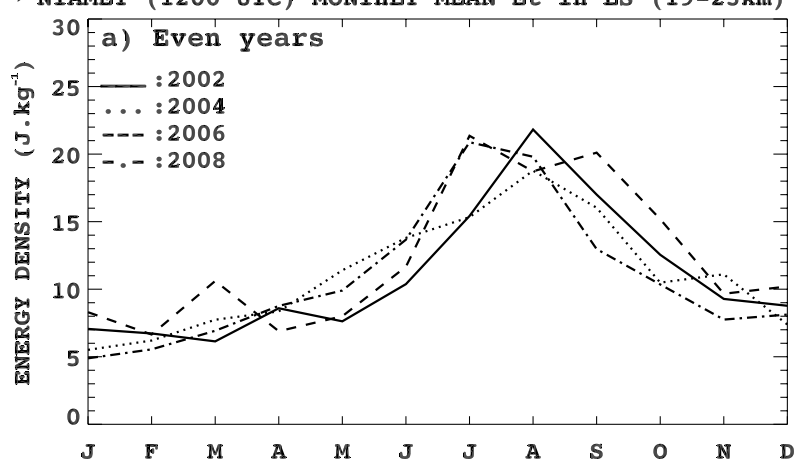

(b) NIAMEY (1200 UTC) MONTHLY MEAN Et in LS $(19-23 \mathrm{~km})$

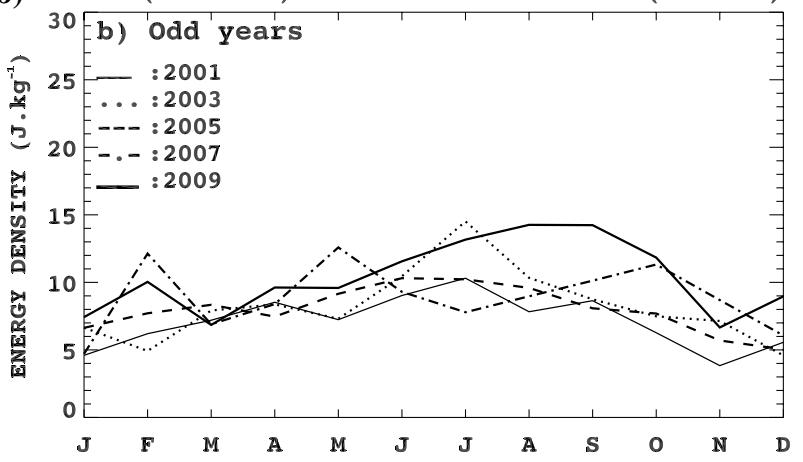

Fig. 15 Monthly mean variations of total energy density above Niamey for 2001 to 2009 for a even years (2002: solid line, 2004: dotted line, 2006: dashed line, and 2008: dash dot), and $\mathbf{b}$ for odd years (2001: thin solid line, 2003: dotted line, 2005: dashed line, 2007: dash dot, and 2009: thick solid line)

during the WAM and $\mathrm{E}_{\mathrm{T}}$ peaks at the QBO E-to-W phase transitions with eastward shear. During the "odd" years, strong westward zonal wind of about $30 \mathrm{~m} \mathrm{~s}^{-1}$ is observed and $\mathrm{E}_{\mathrm{T}}$ maxima occur at the $\mathrm{QBO} \mathrm{W}$-to-E phase transitions with westward shear.

\subsubsection{Concluding remarks}

5.1.3.1 Main results The inter-annual variation exhibits aquasi-2 year modulation of energy density maxima during the WAM period. Large values of energy density maxima are observed at the QBO W-E phase during even years. Seasonal variation of wave energy densities agrees well with the case study of 2006 using AMMA dataset from 2001 to 2009. During the WAM the ratio KE/PE is greater than 3 and supports that there is an energy enhancement around inertial frequency in the gravity-wave energy spectrum. In the "odd" years, energy density maxima occur during the QBO E-phase (westward or negative shear). Westward propagating waves are certainly filtered or damped. Those waves have more energy than the eastward ones, as it is noted in Sect. 4.3. Over West Africa, PE does not reflect the 
variation of total wave energy densities during the WAM in 2001-2009.

5.1.3.2 Intercomparison with other observations In southern tropical zone, Vincent and Alexander (2000) find a QBO-like variation of the energy density of dominant eastward waves with vertical wavelength $\sim 2 \mathrm{~km}$ above Coco Island $12^{\circ} \mathrm{S}$. The authors observe large energy density maxima when largest westward shears occur. Tsuda et al. (2004) (cf. Section 4.1.3) find very low values of KE in the range 20-25 km while the QBO is in E-phase with westward shear; an enhancement of KE is observed in the range 25-30 km while the shear becomes eastward. It is the same situation that was observed between odd and even years.

The comparison with results obtained by Zhang et al. (2012) in the African sector is difficult to carry out. Its instrument averages over $5^{\circ}$ latitude and $10^{\circ}$ longitude. In the African sector, the 8-year mean seasonal behaviour of potential energy PE, averaged between 21 and $34-\mathrm{km}$, reflects the distinct phases of the monsoon period as described in 3.1. However some large PE value area are observed and not explained. As the wavelength range is between 1 and $7 \mathrm{~km}$ then synoptic waves, like Kelvin and Rossby-GWs, the main contributors to PE, are also included.

\subsection{Equatorial region}

\subsubsection{Inter-annual variability}

In the equatorial area, monthly mean time series of $\mathrm{E}_{\mathrm{T}}, \mathrm{KE}$ and even PE above Doula present a biannual modulation with a maximum in May. However the maximum range of variations is smaller than in tropical area (Fig. 16a). The peak in October is present but its intensity has no specific periodic modulation. The main difficulty, to interpret in more details the variation and to stress general conclusion, lies in the number of missing data. The superposition of $\mathrm{E}_{\mathrm{T}}$, $\mathrm{KE}$ and PE in "even" or in "odd" years does not provide any evident common pattern like the one in tropical area (figure not shown).

Main features are $\mathrm{KE}$ and $\mathrm{PE}$ maxima occurring inbetween March to June, and a noticeable variation of PE from 2 to $6 \mathrm{~J} \mathrm{~kg}^{-1}$. Maximum of $\mathrm{E}_{\mathrm{T}}$ observed in the "even" 2006 year during the QBO E-to-W phase, is larger than those in the "odd" years, 2005 and 2007 during the QBO $\mathrm{W}$-to-E phase. The occurrence of the $\mathrm{E}_{\mathrm{T}}$ maxima in May is related to the date of the northward motion of the convection from the Gulf of Guinea to the coastal region near $5^{\circ} \mathrm{N}$, corresponding to the coastal phase and associated with notable changes in the low atmosphere (Thorncroft et al. 2011; Leduc-Leballeur 2011). Thus factors like convection strength shown by OLR proxy, and the ITCZ motion, have an impact on the wave production and then on their number and energy. As an example $\mathrm{E}_{\mathrm{T}}$ in 2004 is equal or lower than $\mathrm{E}_{\mathrm{T}}$ in 2007 , at first the convection seems lower in 2004 i.e. higher value of OLR, i.e. $218 \mathrm{~W} \mathrm{~m}^{-2}$ and 200 $\mathrm{Wm}^{-2}$ respectively for 2004 and 2007 in March-April. The secondary maximum is observed in "odd" years as well as in 'even' years.

\subsubsection{Relationship with $Q B O$}

Figure $3 b$ shows that the lower stratospheric wind above Douala is influenced by the QBO and Fig. 16b presents the variations of $\mathrm{E}_{\mathrm{T}}$, the zonal wind at $21 \mathrm{~km}$ and the OLR. In 2006 while the lower stratospheric wind is small, the propagating waves observed are mostly zonal- westwards as well as eastwards, and with noticeable PE values. The zonal momentum flux points out the importance of the westward momentum (cf. Section 4.3). In 2004 the situation is similar to the one in 2006 but with larger OLR then less convection.

In 2005 and 2007 the lower stratosphere wind is westward and strong then the westward propagating waves are certainly filtered, or damped. Only eastward propagating

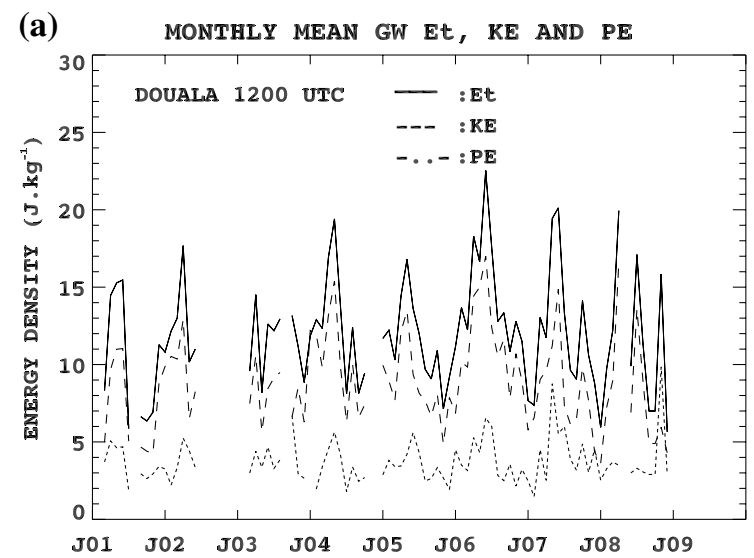

(b)

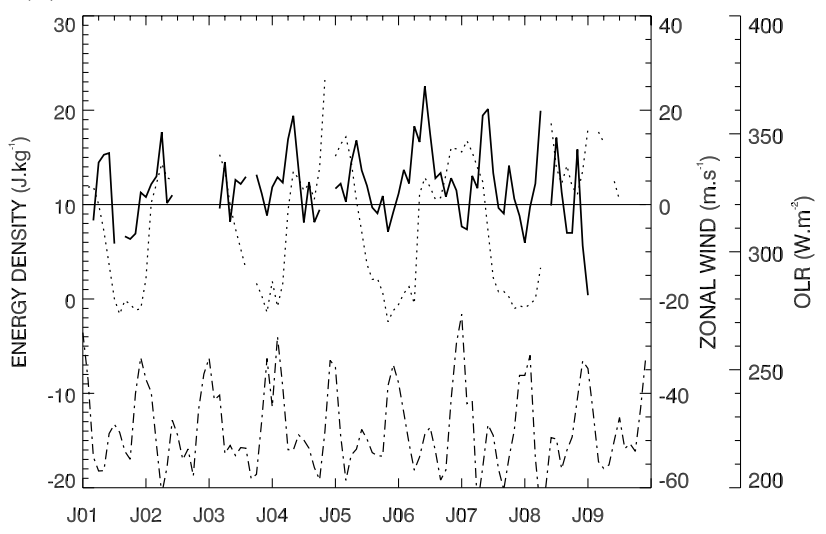

Fig. 16 The same as Fig. 14 but for Douala 
waves may propagate upward. The QBO-only cannot explain the variability of $\mathrm{E}_{\mathrm{T}}, \mathrm{KE}$ and $\mathrm{PE}$, especially around May. Inter-annual convection intensity, as shown on Fig. 15b, may contribute to the inter-annual wave activity variation.

\subsubsection{Concluding remarks}

Missing data do not permit a detailed study of the 9-year time-series of wave activity over the equator. The autumn maximum occurs every year with high $\mathrm{KE} / \mathrm{PE}$ ratio value like in tropical area. The inter-annual variation of spring GW is dependent on not only the QBO phase but also the convection over the Gulf of Guinea, the date of the ITCZ shift... Those last factors have no periodicity.

Analyses of long-term series of upward flux of eastward momentum observed in the equatorial LS due to short period ( $\sim 3$ days), show a QBO-like variation with strongest amplitude occurring during the descending westerly regime (Maruyama 1994; Sato et al. 1994). The authors also highlight that the momentum magnitude of disturbances with 3-days period is as strong as long period Kelvin waves.

Shimizu and Tsuda (2001) carried out daily radiosonde observations for 30 months during October 1993 and March 1996 at Bandung, Indonesia $\left(6.9^{\circ} \mathrm{S}\right)$. They found that in the upper troposphere (UT) an annual cycle of the IGW activity with vertical scale of $2 \mathrm{~km}$ anti-correlated with convective activity appears, but in LS the long-term variations of the wave activity are related to the QBO structure.

\section{Summary and conclusion}

Previous recent numerical studies in stratospheric dynamics and its variability as well as climate have highlighted the need of more observational analyses to provide realistic multiscale couplings and robust parameterization in climate models in order to improve simulation of features of the WAM.

During the intensive observation periods of AMMA in 2006, high-resolution radiosonde observations at six stations in West Africa, two on the equator coast, Douala and Abidjan, four in tropical area-Bamako, Niamey, Agadez and Dakar - provide a first detailed description and annual variation of convective short scale waves with vertical wavelengths less than $4 \mathrm{~km}$ in the lower stratosphere (19$23 \mathrm{~km}$ ) over West Africa. These waves are interpreted as inertia-gravity waves generated by WAM convection. Long time series (2001-2009) of lower resolution radiosonde observations at two stations, a tropical one, Niamey, and an equatorial one, Douala, permit to analyse the impact of the QBO phase on the wave energy densities in the LS.

The main results are as follows:
1. The geographical location, latitude as well as coast versus inland, of the six stations in 2006 permits to point out the close relationship between the annual variation of wave energy densities and the WAM one: during winter season, intrusions of convection from the Guinea Gulf onto the continent, then the ITCZ and convection progress northwards during the monsoon period and return southwards to the Guinea gulf.

2. The annual variation of wave energy densities depends on the time schedule of the different WAM phases and on the convection strength developed.

3. Over the tropical area, short-scale wave activity starts in May-June 2006 and the annual behaviour is characterized by a single peak (around $20 \mathrm{~J} \mathrm{~kg}^{-1}$ ) localized in July-August 2006; a strong contribution of kinetic energy, KE, (85-90 \%) to the total energy density is observed during the WAM.

4. In the tropical LS, in 2006 the 4 annual variations of the wave energy densities are similar. As a consequence wave parameters by gathering the data from those stations are determined and considered representative of the tropical rectangle-like zone, $13^{\circ}-17^{\circ} \mathrm{N}$ latitude, $8^{\circ} \mathrm{E}-17.50^{\circ} \mathrm{W}$ longitude. However for regional models some environmental features may have to be taken into account; for example Dakar being on the coast and Agadez at the foot of Aïr.

5. In the tropical LS (19-23 km), in 2006 the mean (median) intrinsic frequencies, vertical and horizontal wavelengths observed over West Africa with highresolution radiosondes are 1.4-2.2, $\sim 2 \mathrm{~km}$ and 420$1100 \mathrm{~km}$ respectively. The mean intrinsic phase speed is $8 \mathrm{~m} \mathrm{~s}^{-1}$. Those characteristics correspond to IGWs. Their periods are related to the local inertial period by a factor around $1.7 \mathrm{f}$ (median value) i.e. 25-35 h. Even if the observed waves have a quasi-isotropic geographical distribution, the temporal behaviour of zonal momentum flux exhibits a variation with WAM, maximum westward flux, with a magnitude ranging from $8.5 \mathrm{mPa}$ to $11 \mathrm{mPa}$, matching strong $\mathrm{E}_{\mathrm{T}}$ regardless of the tropospheric background winds but likely in relation with the storm-relative propagation characteristics. The upward flux of meridional momentum is different from one site to another it is northwards with values between 2 and $8.5 \mathrm{mPa}$ and observed from May to September during the WAM (period of strong $\mathrm{E}_{\mathrm{T}}$ ).

6. Another characteristic is the KE/PE ratio larger than 2 , which suggests an enhancement of wave energy at near-inertial frequency departing from the simple $5 / 3$ power-law form. In such conditions, as short vertical wavelengths $(<4 \mathrm{~km})$ and inertia-gravity waves, the potential energy, PE, may not be a proxy for convection and be used to estimate total wave energy. From 
above results, in tropical West Africa modelers have to pay care to data they assimilate or use for model validation. With vertical wavelengths larger than $4 \mathrm{~km}$, the contribution of equatorial waves is the most important compared with that of IGWs.

7. Long-term time series of wave energy densities (from January 2001 to December 2009) in the tropics show a year-to-year variation superimposed to convective activity and QBO-like variations. They point out a similar annual variation with higher peak $\left(>18 \mathrm{~J} \mathrm{~kg}^{-1}\right)$ observed in July-August, monsoon period, during the W-phase (descending westerly winds) or even years -2002, 2004, 2004, 2006 and 2008; and erratic variations in the monsoon period with small values during the QBO E-phase (descending easterly wind). Taking into account the wind gradients and results obtained in 2006, westward propagating waves, observed in 2006, are certainly filtered or encounter a critical level during the QBO E-phase. It also means that the eastward propagating waves correspond to weak energy.

8. The equatorial area is more complex. Two periods are observed, the stronger one occurs in March-June the convection is on the ocean, the second one July-September the convection on the land. Furthermore the two stations, Abidjan and Douala, are close in latitude, $5.25^{\circ} \mathrm{N}$ and $4.01^{\circ} \mathrm{N}$, their difference of longitudes, $3.94^{\circ} \mathrm{W}$ and $9.70^{\circ} \mathrm{E}$, is more important, especially their geographical location. Both are on the coast but the Guinea Gulf is south to Abidjan and East to Douala. Their climatology is different. The comparison cannot be fully carried due to the very few data in Abidjan.

9. In the equatorial LS, during March-June 2006, GWs have median intrinsic frequencies, vertical and horizontal wavelengths of $1.4-4 \mathrm{f}, \sim 2 \mathrm{~km}$ and $830-1900 \mathrm{~km}$ respectively. The mean intrinsic phase speed is $7 \mathrm{~m} \mathrm{~s}^{-1}$. Their periods are related to the local inertial period by a factor around $2.75 \mathrm{f}$ (median value) i.e. $44-84 \mathrm{~h}$. The observed waves propagate zonally, roughly equal number eastwards and westwards. The upward flux of the zonal momentum is westwards localized in May with a magnitude of $6.5 \mathrm{mPa}$. The upward fluxes of meridional momentum are positive i.e. northwards and strongest magnitudes are around $3 \mathrm{mPa}$. Temporal behaviour doesn't exhibit a clear variation in relation with $\mathrm{E}_{\mathrm{T}}$ as indicated for tropical area because of lack of data and of too small number of points.

10. A close analyse of the variances points out in a very few cases $<4$ the presence of Kelvin waves in a mode $2-5$ or MRG. The ratio KE/PE is in between 1.5 and 2 and corresponds to the expected value assuming $\mathrm{GW}$ total energy spectrum scaling at $\omega^{-5 / 3}$.

11. During the phase July-November 2006, the mean (median) intrinsic frequencies, vertical and horizon- tal wavelengths observed over West Africa with highresolution radiosondes are $1.2-3, \sim 2$ and $830-1900 \mathrm{~km}$ respectively. The mean intrinsic phase speed is $7 \mathrm{~m} \mathrm{~s}^{-1}$. Those characteristics correspond to IGWs. Their periods are related to the local inertial period by a factor around 1.9 (median value) i.e. 50-100 h. The observed waves propagate zonally, roughly equal number eastwards and westwards.. However waves having more energy are found to propagate westwards. The observed waves are closer to the IGWs in the tropics with KE/PE $>2$.

12. For the equatorial coastal area, the convection and QBO variability impact on the year-to-year variation of wave activity during the March-June period. However no common variations are observed like in the tropics. It may due to variable time for the coastal phase i.e. when rainfall distribution peaks over the African coast around $4^{\circ} \mathrm{N}$ and the strength of convection. The second peak in September - October is also sensitive both to QBO phase and convection. A more complete dataset and detailed analysis are needed to draw a general conclusion.

In perspective, this study will be completed with a mesoscale modeling to deepen short vertical scale wave processes during WAM and their variabilities.

Acknowledgments This work was done during the stay of P. Kafando at LATMOS. The authors acknowledge sincerely the French Ministry of Foreign affairs and LATMOS for her financial support. The publication is financially supported by the laboratory, LACy, at the University of La Réunion and the French project, StraDyVariUS. Based on a French initiative, AMMA was built by an international scientific group and is currently funded by a large number of agencies, especially from France, the United Kingdom, the United States, and Africa. It has been the beneficiary of a major financial contribution from the European Community's Sixth Framework Research Program. Detailed information on scientific coordination and funding is available on the AMMA international Web site (http://www.amma-international.org). The authors also thank the Wyoming University and the NOAA for providing radiosonde observations and OLR data, respectively.

\section{Compliance with ethical standards}

Conflict of interest The authors declare that they have no conflict of interest.

Open Access This article is distributed under the terms of the Creative Commons Attribution 4.0 International License (http://creativecommons.org/licenses/by/4.0/), which permits unrestricted use, distribution, and reproduction in any medium, provided you give appropriate credit to the original author(s) and the source, provide a link to the Creative Commons license, and indicate if changes were made.

\section{References}

Agustí-Panareda A, Beljaars A, Ahlgrimm M, Balsamo G, Bock O, Forbes R, Ghelli A, Guichard F, Köhler M, Meynadier R, Morcrette J-J (2010) The ECMWF re-analysis for the AMMA 
observational campaign. Q J R Meteorol Soc 136:1457-1472. doi: $10.1002 /$ qj.662

Alexander MJ, Holton JR (1997) A model study of zonal forcing in the equatorial stratosphere by convectively induced gravity waves. J Atmos Sci 54:408-419

Alexander MJ, Geller M, McLandress C, Polavarapu S, Preusse P, Sassi F, Sato K, Eckermann S, Ern M, Hertzog A, Kawatani Y, Pulido M, Shaw T, Sigmond M, Vincent R, Watanabe S (2010) Recent developments in gravity wave effects in climate models, and the global distribution of gravity wave momentum flux from observations and models. Q J R Meteorol Soc 136:1103-1124

Allen SJ, Vincent RA (1995) Gravity wave activity in lower atmosphere: seasonal and latitudinal variations. J Geophys Res 100:1327-1350

Baldwin MP, Gray LJ, Dunkerton TJ, Hamilton K, Haynes PH, Randel WJ, Holton JR, Alexander MJ, Hirota I, Horinouchi T, Jones DBA, Kinnersley JS, Marquard C, Sato K, Takahashi M (2001) The quasi-biennial oscillation. Rev Geophys 39:179-229

Berès JH, Alexander MJ, Holton JR (2002) Effects of Tropospheric Wind Shear on the Spectrum of Convectively Generated Gravity Waves. J Atmos Sci 59:1805-1824

Bielli S, Douville H, Poh B (2010) Understanding the West African monsoon variability and its remote effects: an illustration of the grid point nudging methodology. Clim Dyn 35:159-174. doi:10.1007/s00382-009-0667-8

Caccia J-L, Benech B, Klaus V (1997) Space-Time Description of Nonstationary Trapped Lee Waves Using ST Radars, Aircraft, and Constant Volume Balloons during the PYREX Experiment. J Atmos Sci 54:1821-1833. doi:10.1175/1520-0469

Caniaux G, Giordani H, Redelsperger J-L, Guichard F, Key E, Wade M (2011) Coupling between the Atlantic cold tongue and the West African monsoon in boreal spring and summer. J Geophys Res 116:C04003. doi:10.129/20010JC006570

Chane-Ming F, Faduilhe D, Leveau J (2007) Latitudinal and seasonal variability of gravity-wave energy in the South-West Indian Ocean. Ann Geophys 25:2479-2485

Chane Ming F, Chen Z, Roux F (2010) Analysis of gravity-waves produced by intense Tropical cyclones. Ann Geophys 28:531-547

Chao WC, Yang B, Fu X (2009) A revised method of presenting wave number-frequency power spectrum diagrams that reveals the asymmetric nature of tropical large- scale waves. Clim Dyn 33:843-847. doi:10.1007/s00382-008-0494-3

Cook KH, Vizy EK (2006) Coupled Model Simulations of the West African monsoon system: 20th century Simulations and 21st Century Predictions. J Clim 19:3681-3703

Das U, Pan CJ (2013) Strong Kelvin wave activity observed during the westerly phase of QBO-a case study. Ann Geophys 31:581-590

Desaubies YJF (1976) Analytical representation of internal wave spectra. J Phys Oceanogr 6:976-981

Drobinski P, Bastin S, Janicot S, Bock O, Dabas A, Delville P, Reitebuch O, Sultan B (2009) On the late northward propagation of the West African monsoon in summer 2006 in the region of Niger/Mali. J Geophys Res 114:D09108. doi:10.1029/200 8JD011159

Dunkerton TJ (1997) The role of gravity waves in the quasi-biennial oscillation. J Geophys Res 102:26053-26076

Eckermann SD (1996) Hodographic analysis of gravity waves: relationships among Stokes parameters, rotary spectra and crossspectral methods. J Geophys Res 101(D14):19169-19174

Ern M, Preusse P, Alexander MJ, Warner CD (2004) Absolute values of gravity wave momentum flux derived from satellite data. J Geophys Res 109:D20103. doi:10.1029/2004JD004752

Flaounas E, Janicot S, Bastin S, Roca R (2012) The West African monsoon onset in 2006: sensitivity to surface albedo, orography,
SST and synoptic scale dry-air intrusions using WRF. Clim Dyn 38:685-708. doi:10.1007/s00382-011-1255-2

Geller MA, Alexander MJ, Love PT, Bacmeister J, Ern M, Hertzog A, Manzini E, Preusse P, Sato K, Scaife AA, Tiehan Zhou T (2013) A comparison between gravity wave momentum fluxes in observations and climate models. J Clim 26:6383-6405

Gerber EP, Butler A, Calvo N, Charlton-Perez A, Giorgetta M, Manzini E, Perlwitz J, Polvani LM, Sassi F, Scaife AA, Shaw TA, Son SW, Watanabe S (2012) Assessing and understanding the impact of stratospheric dynamics and variability on the earth system. Bull Am Meteorol Soc 93:845-859. doi:10.1175/ BAMS-D-11-00145.1

Gill AE (1982) Atmosphere-ocean dynamics. Academic Press, New York, p 663

Hertzog A, Vial F, Mechoso CR, Basdevant C, Cocquerez P (2002) Quasi-Lagrangian measurements in the lower Stratosphere reveal an energy peak associated with near-inertial waves. Geophys Res Lett 29(8):1229. doi:10.1029/2001GL014083

Holton JR (1992) Waves in the equatorial stratosphere. In: An introduction to dynamic meteorology. 3rd edn. Academic Press, Inc, New York, pp 418-424

Holton JR, Alexander MJ, Boehm MT (2001) Evidence for short vertical wavelength Kelvin waves in the Department of EnergyAtmospheric Radiation Measurement Nauru99 radiosonde data. J Geophys Res 106(D17):20125-20129

Janicot S, Thorncroft SD, Ali A, Asencio N, Berry G, Bock O, Bourles B, Caniaux G, Chauvin F, Deme A, Kergoat L, Lafore JP, Lavaysse C, Lebel T, Marticorena B, Mounier F, Nedelec P, Redelsperger JL, Ravegnani F, Reeves CE, Roca R, de Rosnay P, Schlager H, Sultan B, Tomasini M, Ulanovsky A, ACMAD Forecasters Team (2008) Large-scale overview of the summer monsoon over West Africa during the AMMA field experiment in 2006. Ann Geophys 26:2569-2595

Kafando P, Chane-Ming F, Petitdidier M (2008) Climatology of gravity wave activity during the West African monsoon. Ann Geophys 26:4081-4089

Karoly DJ, Roff GL, Reeder MJ (1996) Gravity wave activity associated with tropical convection detected in TOGA COARE sounding data. Geophys Res Lett 23:261-264

Kawatani Y, Watanabe S, Sato K, Dunkerton TJ, Miyahara S, Takahashi M (2010a) The roles of equatorial trapped waves and internal inertia-gravity waves in driving the quasi-biennial oscillation. Part I: zonal mean wave forcing. J Atmos Sci 67:963-980

Kawatani Y, Watanabe S, Sato K, Dunkerton TJ, Miyahara S, Takahashi M (2010b) The roles of equatorial trapped waves and internal inertia-gravity waves in driving the quasi-biennial oscillation. Part II: three-dimensional distribution of wave forcing. J Atmos Sci 67:981-997

Kim Y-H, Chun H-Y (2015) Momentum forcing of the QBO by equatorial waves in recent reanalyses. Atmos Chem Phys 15:65776587. doi:10.5194/acp-15-6577-2015

Lavaysse C, Flamant C, Janicot S, Parker DJ, Lafore J-P, Sultan B, Pelon J (2009) Seasonal evolution of the West African heat low: a climatological perspective. Clim Dyn 33:313-330

Lavaysse C, Flamant C, Janicot S (2010) Regional-scale convection patterns during strong and weak phases of the Saharan heat low. Atmos Sci Lett. doi:10.1002/asl.284

Le Sommer J, Teitelbaum H, Zeitlin V (2006) Global estimates of equatorial inertia-gravity wave activity in the stratosphere inferred from ERA40 reanalysis. Geophys Res Lett 33:L07810. doi:10.1029/2005GL024873

Lebel T, Parker DJ, Flamant C, Bourlès B, Marticorena B, Mougin E, Peugeot C, Diedhiou A, Haywood JM, Ngamini JB, Polcher J, Redelsperger J-L, Thorncroft CD (2010) The AMMA field campaigns: multiscale and multidisciplinary observations in the 
West African region. Q J R Meteorol Soc 136:8-33. doi:10.1002/ qj. 486

Leduc-Leballeur M, de Coëtlogon G, Eymard L (2011) Air-sea interaction in the Gulf of Guinea at intraseasonal timescales: wind bursts and coastal precipitation in boreal spring. Q J R Meteorol Soc 137:992-1003. doi:10.1002/qj.808

Liebmann B, Smith CA (1996) Description of a complete (interpolated) outgoing longwave radiation dataset. Bull Am Meteorol Soc 77:1275-1277

Lothon M, Saïd F, Lohou F, Campistron B (2008) Observation of the diurnal cycle in the lower troposphere of West Africa. Mon Weather Rev 136:3477-3500. doi:10.1175/2008MWR2427.1

Maruyama T (1994) Upward transport of westerly momentum due to disturbances of the equatorial lower stratosphere in the period range of about 2 days -a Singapore Data Analysis for 19831993. J Meteorol Soc Jpn 72(3):423-431

Maury P, Lott F, Guez L, Duvel JP (2013) Tropical variability and stratospheric equatorial waves in the IPSLCM5 model. Clim Dyn 40:2331-2344. doi:10.1007/s00382-011-1273-0

Mc-Landress C, Alexander MJ, Wu DL (2000) Microwave limb sounder observations of gravity waves in the stratosphere: a climatology and interpretation. J Geophys Res 102(D9):11947-11967

Nath D, Ratnam MV, Jagannadha Rao VVM, Krishna Murthy BV, Vijaya Bhaskara Rao S (2009) Gravity wave characteristics observed over a tropical station using high-resolution GPS radiosonde soundings. J Geophys Res 114:D06117. doi:10.1029/200 8JD011056

Nuret M, Lafore JP, Bock O, Guichard F, Agusti-Panareda A, N'Gamini JB, Redelsperger JL (2008) Correction of humidity bias for Vaisala RS80-A sondes during the AMMA 2006 observing period. J Atmos Ocean Tech 25:2152-2158

Okumura Y, Xie SP (2004) Interaction of the Atlantic equatorial cold tongue and the African monsoon. J Clim 17:3589-3602

Pandya RE, Alexander MJ (1999) Linear stratospheric gravity waves above convective thermal forcing. J Atmos Sci 56:2434-2446

Parker DJ, Fink A, Janicot S, Ngamini JB, Douglas M, Afiesimama E, Augusti-Panareda A, Beljaars A, Dide F, Diedhou A, Lebel T, Polcher J, Redelsberger J-L, Thorncroft CD, Wilson GA (2008) The AMMA radiosonde program and its implications for the future of atmospheric monitoring over Africa. Bull Am Meteorol Soc 89:1015-1027

Plougonven R, Teitelbaum H, Zeitkin V (2003) Inertia gravity wave generation by the tropospheric midlatitude jet as given by the fronts and Atlantic Storm-Track Experiment radio soundings. J Geophys Res 108:4686. doi:10.1029/2003JD003535

Ratnam MV, Tetzlaff G, Jacobi C (2004) Global and seasonal variations of stratospheric gravity wave activity deduced from the CHAMP/GPS satellite. J Atmos Sci 61:1610-1620

Ratnam MV, Narendra Babu A, Jagannadha Rao VVM, Vijaya Bhaskar Rao S, Narayana Rao D (2008) MST radar and radiosonde observations of inertia-gravity wave climatology over tropical stations: source mechanisms. J Geophys Res 113:D07109. doi:10.1029/2007JD008986

Redelsperger J-L, Thorncroft CD, Diedhiou A, Lebel T, Parker DJ, Polcher J (2006) African monsoon multidisciplinary analysis: an international research project and field campaign. Bull Am Meteorol Soc 87:1739-1746

Salby ML, Garcia RR (1987) Transient response to localized episodic heating in the tropics. Part I: excitation and short-time near-field behavior. J Atmos Sci 44:458-498

Sato K, Dunkerton TJ (1997) Estimates of momentum flux associated with equatorial Kelvin and gravity waves. J Geophys Res 102(D22):26247-26261

Sato K, Hasegawa F, Hirota I (1994) Short-period disturbances in the equatorial lower stratosphere. J Meteorol Soc Jpn 72:423-432
Sato K, Yamamori M, Ogino SY, Takahashi N, Tomikawa Y, Yamanouchi T (2003) A meridional scan of the stratospheric gravity wave field over the ocean in 2001 (MeSSO2001). J Geophys Res 108(D16):4491. doi:10.1029/2002JD003219

Schirber S, Manzini E, Krismer T, Giorgetta M (2015) The quasibiennial oscillation in a warmer climate: sensitivity to different gravity wave parameterizations. Clim Dyn 45:825-836. doi:10.1007/s00382-014-2314-2

Shimizu A, Tsuda T (2001) Seasonal and QBO-related variations in gravity wave activities observed with radiosondes at Bandung, Indonesia. J Meteorol Soc Jpn 79(1):185-200

Sultan B, Janicot S (2003) The West African monsoon dynamics. Part II: the "preonset" and "onset" of the summer monsoon. J Clim 16(21):3407-3427

Thorncroft CD, Nguyen H, Zhang C, Peyrillé P (2011) Annual cycle of the West African monsoon: regional circulations and associated water vapour transport. Q J R Meteorol Soc 137:129-147

Tsuda T, Murayama Y, Wiryosumarto H, Harijono SWB, Kato S (1994a) Radiosonde observations of equatorial atmosphere dynamics over Indonesia. Part 1: equatorial waves and diurnal tides. J Geophys Res 99(D5):10491-10505

Tsuda T, Murayama Y, Wiryosumarto H, Harijono SWB, Kato S (1994b) Radiosonde observations of equatorial atmosphere dynamics over Indonesia. Part 2: characteristics of gravity waves. J Geophys Res 99(D5):10507-10516

Tsuda T, Ratnam VM, May PT, Alexander MJ, Vincent RA, McKinnon A (2004) Characteristics of gravity waves with short vertical wavelengths observed with radiosonde and GPS occultation during DAWEX (Darwin Area Wave Experiment). J Geophys Res 109:D20S03. doi:10.1029/2004JD004946

VanZandt TE (1982) A universal spectrum of buoyancy waves in the atmosphere. Geophys Res Lett 9(575):578

VanZandt TE, Fritts DC (1989) A theory of enhanced saturation of the gravity wave spectrum due to increases in atmospheric stability. Pure appl Geophys 130:399-420

Vincent RA (1984) Gravity-wave motions in the mesosphere. J Atmos Terr Phys 46:119-128

Vincent RA, Alexander MJ (2000) Gravity waves in the tropical lower stratosphere: an observational study of seasonal and interannual variability. J Geophys Res 105(D14):17971-17982

Vincent RA, Allen SJ, Eckermann SD (1997) Gravity wave parameters in the lower stratosphere. In: Hamilton K (ed) Gravity wave processes: their parameterization in global climate models. Springer, Berlin, pp 7-25

Wada K, Nitta T, Sato K (1999) Equatorial inertia-gravity waves in the lower stratosphere revealed by TOGA-COARE IOP data. J Meteorol Soc Jpn 77(3):721-736

Wang L, Geller MA (2003) Morphology of gravity-wave energy as observed from 4 years (1998-2001) of high vertical resolution U.S. radiosonde data. J Geophys Res 108(D16):4489. doi:10.10 29/2002JD002786

Wang L, Geller MA, Alexander MJ (2005) Spatial and temporal variations of gravity wave parameters. Part I: intrinsic frequency, wavelength, and vertical propagation direction. J Atmos Sci 62:125-142

Xue XH, Liu HL, Dou XK (2012) Parameterization of the inertial gravity waves and generation of the quasi-biennial oscillation. J Geophys Res 117:D06103. doi:10.1029/2011JD016778

Zhang Y, Xiong J, Liu L, Wan W (2012) A global morphology of gravity wave activity in the stratosphere revealed by the 8-year SABER/TIMED data. J Geophys Res 117:D21101. doi:10.1029/ 2012JD017676 